\title{
MÁS ALLÁ DEL PUENTE: ALGUNAS CONSIDERACIONES SOBRE EL ROL DE LA POLÍTICA CRIMINAL
}

\section{Rodrigo Cristhian CARdozo POZO*}

RESUMEN: Ante la actual imposibilidad de consensuar un concepto de politica criminal, en este articulo se parte de la formal, pero aceptada distinción, entre politica criminal como actividad del Estado y politica criminal como actividad cientifica. Precisados dichos conceptos, se da paso al rol de esta. Para ello se analizan tres visiones, esto es: como lege ferenda, como puente o, ubicada desde las bases del sistema. A partir de la última plataforma conceptual, puede explicarse de mejor manera el rol de la politica criminal en la actualidad. Una politica criminal que ya no necesita encontrar en el Derecho penal una barrera infranqueable, sino una que, siendo coherente con la forma de Estado en la que se despliega, enfrente la problemática social de la delincuencia desde esos principios.

PALABRAS CLAVE: Política criminal - criminología - dogmática penal - rol de lege ferenda - rol de puente - integración al sistema.

\section{BEYOND THE BRIDGE: SOME CONSIDERATIONS ABOUT THE ROLE OF CRIMINAL POLICY}

ABSTRACT: In the face of the current impossibility to find a consensus regarding the concept of Criminal Policy, this article deals with the formal, yet accepted distinction, between Criminal Policy as an activity of the State versus Criminal Policy as a scientific activity. Being both concepts defined, three points of view are analyzed for its role: Criminal Policy as lege ferenda, as a bridge or as a base of the system. Based on the latter concept, the current role of Criminal Policy can be better understood. This type of Criminal Policy no longer encounters obstacles within the Criminal Law. Instead, it confronts the social problems of delinquency in coherence to the principles of the according form of government in which it develops.

\footnotetext{
Abogado. Licenciado en Ciencias Jurídicas y Sociales. Profesor Instructor de Derecho Penal de la Facultad de Derecho de la Universidad de Atacama. Doctorando del programa "Problemas Actuales de Derecho Penal", Facultad de Derecho, Universidad de Salamanca. Correo electrónico: rcardozo@uda.cl y rcardozo@usal.es Fecha de recepción: 11 de agosto de 2007. Fecha de aprobación: 4 de junio de 2009.
} 
KEY WORDS: Criminal Policy - Criminology - Criminal Dogmas - Role of lege ferenda - Role of bridge - Integration to the system.

SUMARIO: 1) Sobre el concepto de politica criminal: (1.1.) Acerca de las dificultades en la delimitación; (1.2.) Aproximaciones a un concepto de politica criminal. 2) politica criminal como manifestación de poder y como manifestación de saber: un distingo necesario: (2.1.) La política criminal como "manifestación de poder"; (2.2.) La politica criminal como "manifestación de saber". (2.3) Sintesis: concepto de trabajo 3) Tres visiones del rol de la política criminal: (3.1.) Politica criminal con función de "Lege Ferenda"; (3.2.) Politica criminal como "Puente" entre la Criminología y la Dogmática Jurídico Penal; (3.2.1.) Evolución por "Asentamiento";(3.2.2.) La Función del "Puente"; (3.3.) La politica criminal "desde las bases" del Sistema Penal. (4.) Toma de postura: Más que Unión, integración.

\section{1) SOBRE EL CONCEPTO DE POLÍTICA CRIMINAL}

\section{(1.1) ACERCA DE LAS DIFICULTADES EN LA DELIMITACIÓN}

¿Qué es la política criminal? Pues en principio una buena pregunta. Una de aquellas catalogables en la columna de "insoslayables" para los tiempos que corren en el ámbito de las ciencias penales. Este, bien es conocido, se ha caracterizado por el gran acuerdo existente respecto de la creciente trascendencia de la política criminal, sin perjuicio de no existir semejante concierto ${ }^{1}$ en cuanto al contenido, límite y funciones de la misma².

A primera vista resulta extrańo, aunque muy frecuente, que lo que debiera ser un concepto asentado, teniendo en cuenta la particular importancia que seńalábamos viene cobrando, tenga una dificultad tal que resulte ya en sí complejo reconocer aquello que parece ser lo "mínimo" a exigir a la política criminal: establecer cuando menos los deslindes más o menos consensuados de una definición ${ }^{3}$.

1 En esta línea Baratta reconoce en la indeterminabilidad del "instrumental" la razón de la complejidad y con ello de la tortuosa conceptualización. Baratta Alessandro (1998). "Política Criminal entre la Política de seguridad y la política social en países con grandes conflictos sociales y políticos". En AA.VV., Memorias Foro de Politica Criminal, Bogotá: Universidad Javeriana, pp. 25-78 y Baratta Alessandro (1999). "La política criminal y el derecho penal de la constitución: nuevas reflexiones sobre el modelo integrado de ciencias penales". Revista de la Facultad de Derecho de la Universidad de Granada, No 2, p. 89. En este sentido, entre otros, Baigún David (1978). "Política Criminal y Derecho Penal". Revue Internationale de Droit Pénal, No 1, p. 31; Silva Sánchez, Jesús (1997). "Política Criminal en la Dogmática: Algunas Cuestiones sobre su Contenido y Límite". En AA.VV, Politica criminal y Nuevo Derecho Penal, Libro Homenaje a Claus Roxin, Barcelona, pp. 1819; Baratta (1998) 25 y Baratta (1999) 89. ria de ardiente discusión desde que las dos últimas disciplinas aparecieron formalmente, es 
Naturalmente que en una dinámica como la que se ha venido manteniendo, la precisión terminológica no puede ser una de sus características más destacadas ${ }^{4}$. Está fuera de discusión la capital importancia que tiene la utilización de un lenguaje rigoroso en nuestra área de conocimiento ${ }^{5}$, no obstante, se está conteste también que ello, en el plano de la política criminal, no se ha visto cumplido ${ }^{6}$.

Dentro de ese contexto que he seńalado, no es difícil encontrarse definiciones (¿declaraciones?) que solo vienen a dejar testimonio por escrito de las dificultades existentes en la delimitación conceptual. Punto este que se vislumbra como uno de los pocos sobre el que la doctrina encuentra un cierto acuerdo7. Muy gráfica respecto de lo que se viene seńalando, la tantas veces citada DélmasMarty expresa: "¿Y si política criminal no fuera más que palabras vacías? ¿O, más bien, palabras demasiado llenas por la pluralidad de significados que se les atribuye, y absolutamente distintas por la multiplicidad de manifestaciones y matices que cada cultura les ha aportado? ¿Un cuadro, quizá, demasiado laxo, del que las imágenes continuamente huyen? ${ }^{8}$.

decir, al menos cuando Liszt, a finales del pasado siglo, señaló que el primero es el límite de la segunda." Fernández Carrasquilla, Juan (1984). "Hacia un derecho penal de la liberación”. En AA.VV., Criminologia Crítica, I seminario, Medellín: CCUM, p. VII.

4 Sobre ello seńala Binder: "Esto se debe a que a lo largo del tiempo al término "política criminal" se le han asignado muchos y diversos significados. Ha tenido el significado... de un determinado aspecto de la política pero que también se la ha considerado como una determinada "ciencia". En ocasiones se lo ha referido a una cierta escuela. En otras, se lo usó para englobar a todas las escuelas de pensamiento sobre este tema. Obviamente, la proliferación de acepciones ha generado confusión." Binder, Alberto (1997). Politica Criminal: De la Formulación a la Praxis, Buenos Aires: Ad-Hoc, p. 28.

5 Consideración que por lo demás no atańe en exclusiva a la política criminal. Sobre la polisemia de importantes vocablos, citando a Bentham, señala Pérez Luño: “...palabras tales como leyes, derechos, seguridad, libertad... son términos que se emplean con gran frecuencia en la creencia de que hay acuerdo sobre su significado, sin reparar que tales afirmaciones tienen un gran número de acepciones distintas. De ahí que usarlas sin tener clara idea de su sentido es ir de error en error." Pérez Luño, Antonio (2005). Derechos Humanos, Estado de Derecho y Constitución, Madrid: Tecnos, pp. 28-29.

6 En este sentido: Baratta, Alessandro (1998) 25-78; Borja Jiménez, Emiliano (2003a). "Sobre el concepto de política criminal. Una aproximación a su significado desde la obra de Claus Roxin". Anuario de Derecho Penal y Ciencias Penales, Vol. LVI, p. 118; Cerezo Mir, José (2004). Curso de Derecho Penal Español, Parte General, Tomo I, Madrid: Tecnos, p. 88; Quintero Olivares, Gonzalo (2004). Adonde va el Derecho Penal. Reflexiones sobre las Leyes Penales y los Penalistas Españoles, Madrid: Thomson-Civitas, p. 39. Tachándola, incluso, de "agujero negro difícil de llenar de contenido". Zúñiga Rodríguez, Laura (2001). Politica Criminal, Madrid: Colex, p. 17.

7 En este sentido, y crítico respecto de la capacidad encubridora de la amplitud conceptual, Ortiz de Urbina Gimeno, Iñigo (2004). "La referencia político-criminal en el derecho penal contemporáneo (Es el derecho penal la barrera infranqueable de la política criminal, o se orienta por ella). En Emilio Octavio de Toledo y Ubieto, Manuel Gurdiel Sierra, Emilio Cortés Bechiarelli (Coords.). Estudios penales en recuerdo del Profesor Ruiz Antón, Valencia: Tirant lo Blanch, pp. 859-860.

8 Délmas-Marty, Mirelle (1986). Modelos Actuales de Politica Criminal, traducción dirigida por Barbero Santos, Marino. Madrid: SGTMJE, p. 19. 
Es precisamente este "caleidoscópico" escenario" de términos diversos el que ha llevado a parte de la doctrina a reconocer cierto abatimiento en la tarea de lograr un concepto unívoco por ser esta una labor, según Silva Sánchez, carente de sentido ${ }^{10}$. Ahora bien, no se trata solo de encender las alarmas y abandonarnos luego a un escepticismo rotundo. El real aporte de la perspectiva político criminal no requiere solo de fortalecer sus innegables potencialidades, sino también de dar respuesta a las críticas sobre sus falencias. Sobre dicha premisa, y teniendo en cuenta las circunstancias reseñadas, es que, sin pretender resolver la problemática de los deslindes del concepto en términos definitivos, se opta por el planteamiento de un concepto que destaque la necesaria vinculación y correspondencia de la política criminal con el marco de referencia que le da sustento: el Estado social y democrático de derecho en la que se enmarca.

Así, y a fin de acercarnos a un concepto tal de política criminal, en el siguiente punto se realizará una síntesis evolutiva de la misma que vaya sentando algunas bases en dicha dirección.

\section{(1.2) APROXIMACIONES A UN CONCEPTO DE POLÍTICA CRIMINAL}

Habitualmente la política criminal ha sido esencialmente caracterizada en función de su tarea crítica respecto del Derecho vigente, de la que devendría una consecuente propuesta de modificación de las normas que fuesen objeto de dicha labor ${ }^{11}$.

Este aspecto, entre otros, Borja Jiménez, Emiliano (2003). Curso de Politica Criminal, Valencia: Tirant lo Blanch, pp. 21-37; Göppinger, Hans (1975). Criminologia, traducción de Schwarck, Luisa y LuZÁrraga, Ignacio, Madrid: Reus, pp. 18-21; Schüler-Springorum, Horst (1989). Cuestiones Básicas y estrategias de la Politica Criminal, traducción de ElBerT, Alberto, Buenos Aires: Depalma, pp. 7-28; Blanco Lozano, Carlos (2005). "Dogmática, Política Criminal y Criminología en el Sistema del Derecho Penal" en Cuadernos de Politica Criminal, No 86, pp. 5-29; López-Rey y Arrojo, Manuel (1978) en Criminologia, Madrid: Aguilar Ediciones, pp. 340-349; Serrano Gómez, Alfonso (1980). "Dogmática jurídicapolítica criminal-criminología como alternativa de futuro" en Anuario de Derecho Penal y Ciencias Penales, T. XXXIII, Fasc. I, pp. 611-639; ZIPF, Heinz (1979). Introducción a la Politica Criminal, traducción de Miguel Izquierdo Macías Picabea, Madrid: Edersa, pp. 1-14; Zaffaroni, Eugenio Raúl (1993). Criminologia. Aproximación desde un Margen, Bogotá: Temis, pp. 20-21; ZúNígA (2001) pp. 21-24. SiLVA (1997) 19.

11 No se me escapa que el término política criminal es utilizado ya con anterioridad y con diverso contenido de los autores y forma aquí seńalada. Y es que la historia de la política criminal es larga y oscura, pero a pesar de ello, sin perjuicio de no existir acuerdo en su origen, esta ha sido marcada con Kleinsrod (1793), Feuerbach (1801) o Henke (1823), por citar a los más renombrados. Ahora bien, me parece que no resulta oportuno extenderme a esos ámbitos, por ser estas tan breves páginas. Sobre ello Von LiszT, Franz (1914). Tratado de Derecho Penal, traducción de la $18^{a}$ edición alemana y adicionado con Historia del derecho penal en Espańa por Quintiliano Saldaña, Tomo I, Madrid: Reus, pp. 9-12, y en el Tomo II de la misma obra, traducido de la 20a edición alemana por Luis JiMÉNEZ DE Asúa y adicionado con el derecho penal español por Quintiliano Saldaña, Madrid: Reus, pp. 42-78. Debe mencionarse que hay quien considera a BecCaria como el "verdadero padre de la Política criminal", ZÚNIGA, Laura (2001) 75-77. Sobre la real importancia de BECCARIA y la recepción, o no, de su pensamiento en Latinoamérica ZaFfaroni, Raúl (1989). "La influencia del 
Visión esta que venía a encasillarla, básicamente, en el ámbito de la "lege ferenda"12.

De la asignación de esta tradicional función buen ejemplo encontramos ya en Von Liszt quien, desde la perspectiva dual en la que se sustentaba ${ }^{13}$, se refería a ella en los siguientes términos: "La política criminal nos da el criterio para la apreciación del Derecho vigente y nos revela cuál es el que debe regir"14. Asignando también dicho quehacer, el profesor Jiménez de Asúa identificaba la política criminal como una parte, un elemento más del Derecho penal, como un "...corolario de la dogmática: crítica y reforma" ${ }^{15}$. De semejante signo se manifestaron también Antón Oneca, Saldaña y Langle ${ }^{16}$.

Dentro de la misma tendencia interpretativa, en Alemania, puede citarse a Göppinger, destacando que la política criminal se encarga de la política de reforma del Derecho penal, y de la ejecución del mismo para, "la lucha contra el crimen por medio del derecho penal"17. Sintético sobre la perspectiva que se viene comentando citaremos, por último, a Kaiser quien en este sentido explica que ante la imposibilidad de resultar completamente satisfactorio un régimen de protección social, cualquier sistema, si se tiene como parámetro la criminalidad y sus efectos secundarios, la política criminal (criminalista, dice este autor) encontraría su "punto de gravedad en la renovación del derecho penal, la reforma

pensamiento de Cesare Beccaria sobre la política criminal en el mundo". Anuario de Derecho Penal y Ciencias Penales, T. XLII, Fasc. I, pp. 521-551.

Así, por todos, en este sentido Mir Puig, Santiago (1994). El Derecho Penal en el Estado Social y Democrático de Derecho, Barcelona: Editorial Ariel, pp. 14, 24, 25; Millitelo, Vincenzo (2003). "Dogmática penal y política criminal en perspectiva europea". En Luis Arroyo Zapatero, Ulfrid Neumann, Adán Nieto Martín (Coords.), Crítica y Justificación del Derecho penal en el Cambio de Siglo, Cuenca: Ediciones Universidad Castilla-La Mancha, pp, 42-43; Ortiz de Urbina Gimeno, Ińigo (2004) 866.

13 En el mismo sentido por todos, Roxin, Claus (1972). Politica Criminal y Sistema del Derecho Penal, traducción de Francisco Muñoz Conde, Barcelona: Editorial Bosch, pp. 32-35; o, más reciente, Gómez Martín, Víctor (2007). El derecho penal de autor, Valencia: Tirant lo Blanch, pp. 36-51.

14 Von Liszt (1914) 3.

15 Jiménez de Asúa, Luis (1977). Tratado de Derecho Penal, Parte General, Tomo I, Buenos Aires: Losada, p. 175.

16 Señalaba el primero que la ciencia del Derecho Penal es a su vez Política criminal, en el sentido de ser crítica de las instituciones vigentes y de la preparación de su propia reforma, de acuerdo a lo que él denominó "ideales jurídicos", mismos que se irían configurando conforme a las transformaciones sociales (histórico-culturales). ANTÓN ONECA, José (1986). Derecho Penal, Parte General, $2^{a}$ edición anotada y puesta al día por Hernández, José y Beneytez, Luis, Madrid: Akal, p. 25. Ya antes, también en España, opinaba Saldaña que la política criminal presenta dos funciones principales. La primera referida a una tarea crítica de la legislación penal vigente, a la luz de los fines del Derecho y de la pena, y la observación de sus resultados; y la segunda, encaminada a efectuar proposiciones para la reforma del Derecho penal actual. Von Liszt (1914) 63. En esta misma línea, Langle otorgaba a la política criminal la función de indicar los fines para el sistema penal y crear una legislación que respondiera a los mismos. De ahí que reconociera en esta sus dos funciones: "Es critica y legislativa, somete a examen el Derecho vigente y prepara el del porvenir". LANGLE, Emilio (1927). La teoria de la Política Criminal, Madrid: Reus, p. 174. (Cursiva en el original) 
de la justicia y sistema de penas" ${ }^{18}$. Por ello, según el mismo autor, la política criminal se basa en "la expectativa de realizar la óptima solución de la política criminalista" ${ }^{19}$, búsqueda que vendría a explicar que muchas veces se conceptúen como equivalentes política criminal y reforma del derecho penal ${ }^{20}$.

Por razones de espacio, en este punto inicial debe ya destacarse que, básicamente, la evolución de la política criminal no se ha distinguido por la supresión de las funciones que se han venido señalando ${ }^{21}$, si no que se caracteriza, más bien, por la incorporación, la adición, el asentamiento, de nuevas tareas a las ya existentes, sin perjuicio, claro está, de las diversas tendencias que ha ido adoptando de acuerdo a las circunstancias socioculturales de cada época ${ }^{22}$. De esta forma, en nociones más actuales, lo que se ha venido confeccionando es una suerte de "ampliación inventarial" del concepto, en base a la progresiva yuxtaposición de funciones ańadidas, más que una sucesiva sustitución de los elementos conformantes del mismo, que permita ir delineando una silueta contenedora. Es de esta manera que, como señala Serrano Gómez: "se extiende la política criminal a la prevención general y especial, a la interpretación de la ley por los tribunales, al proceso penal, ejecución de la pena, sistemas penitenciarios, $y$, en consecuencia, resocialización del delincuente" 23 .

Es, justamente, en esa forma de evolución de la política criminal donde puede encontrarse una de las causas a los aprietos conceptuales a que se ha hecho referencia al comenzar estas líneas. Esa falta de criterio uniforme sobre su contenido, objeto y función. Y es que a partir de la forma en que se entendió la política criminal (crítica del derecho vigente y propuesta de lege ferenda) las interpretaciones y agregaciones, han sido tantas y tan variopintas que se ha llegado a esta actualidad en la que predomina abiertamente el desconcierto ${ }^{24}$, ha perdido, parafraseado a Zaffaroni, todo contenido semántico ${ }^{25}$.

KAISER, Günther (1983). Criminologia. Una introducción a sus fundamentos cientificos. Traducción Belloch, José, Madrid: Espasa-Calpe, p. 60.

19 En el mismo sentido señala Schüler-Springorum: "Sin embargo, la política criminal es tenida con frecuencia, y no por excepción, como de sentido equivalente a la reforma penal." SCHüLER-SPRINGORUM (1989) 9.

KaISER, Günther (1983) 60.

Es más, no pocos son los autores que continúan definiéndola casi exclusivamente de acuerdo a esta función, así por ejemplo Cerezo (2004) 88-90; Calderón Cerezo, Ángel y Choclán Montalvo, José (1999). Derecho Penal, Parte General, Tomo I, Barcelona: Bosch, pp.17-18; Cuello Contreras, Joaquín (1996). El Derecho Penal Español, Parte General, Madrid: Civitas, p.43; Romeo Casabona, Carlos (1997). Dogmática Penal, Politica Criminal y Criminología en evolución (presentación). En Romeo Casabona, Carlos (editor), Dogmática Penal, Politica Criminal y Criminología en evolución, Tenerife: CECUL, p. 12; Sainz Cantero, José (1979). Lecciones de Derecho Penal, Parte General, Tomo I, Barcelona: Bosch, p. 93. Sobre las distintas corrientes que han ido marcando este desarrollo, por todos, Herrero Herrero, César (2007). Politica Criminal integradora, Madrid: Dykinson, pp. 81-90. Serrano Gómez (1980) p. 617. En sentido parecido Zaffaroni, Eugenio; Aliaga Slokar, Alejandro (2002). Tratado de Derecho Penal, Parte General, Buenos Aires: Ediar, pp. 155-157. En este sentido, Serrano Gómez (1980) 616.

25 ZaFfaroni, Eugenio Raúl (1998). "La Ingeniería institucional criminal (Sobre la necesaria interdisciplinariedad constructiva entre Derecho Penal y Politología)". En Ana Messuti 
Teniendo en cuenta lo anterior, es que se han ido levantado algunas "plataformas de observación" que permitan apreciar de mejor manera las distintas tendencias contenidas en lo que se conoce como política criminal. De esta manera la doctrina ha ido estableciendo ciertas distinciones, a modo de "marcas", para hacer posible un análisis más fructífero. Así, por ejemplo, se ha dicho que debe distinguirse entre una perspectiva "extensiva" y otra "estricta" de la política criminal. La primera se caracterizaría por la inclusión dentro de ella de un objetivo preventivo, mismo que no se encuentra en la segunda, pues estaría referido meramente a la represión con eficacia de actividades ilícitas por parte del Estado ${ }^{26}$.

Muñoz Conde destaca la función reformista de la política criminal, a la que el autor llega a través de la labor crítica de la Dogmática Penal ${ }^{27}$, en un claro acuerdo con lo que Jiménez de Asúa había propuesto ya muchos ańos antes ${ }^{28}$. En Latinoamérica, por último, se puede destacar la perspectiva que sobre esta arista tiene Fernández Carrasquilla, quien distingue dentro del concepto de política criminal, una perspectiva del "Ser" y otra del "Deber ser". La primera asimilada a los medios que oficialmente utilizará el Estado para prevenir la delincuencia, y la segunda se referiría a la descripción de estos medios, pero también, a la fijación de esa práctica estatal a los principios y valores del sistema específico de que se trate ${ }^{29}$.

Desde un enfoque diferente de aquellas líneas generales que se han venido indicando, encontramos la posición del profesor Baratta. Este, desde una perspectiva más categórica, extiende el concepto de política criminal y, consecuentemente con ello, también su objetivo y función. Así, sustentado desde una

(Coord.), Perspectivas Criminológicas: en el umbral del tercer milenio, Montevideo: Fundación de cultura universitaria, p. 108.

SAINZ (1979) 92. En sentido parecido, Rodríguez Devesa establece ciertos distingos al interior del concepto de política criminal. Así, se refiere a una encargada de lo que denomina "problemas utilitarios que presenta la realidad en la lucha contra el delito" y otra abocada a buscar las soluciones legislativas más adecuadas a situaciones concretas (ejemplificando con un auge de los delitos contra la vida o la propiedad). Para este autor la primera se encontraría dentro de la Criminología y la segunda, a su juicio "inseparablemente", en el ámbito del Derecho penal. Rodríguez Devesa, José María; Serrano Gómez, Alfonso (1994). Derecho Penal Español, Parte General, Madrid: Dykinson, p. 18. Además Rodríguez Devesa, José María (1979). "El Derecho Comparado como Método de Política Criminal". Anuario de Derecho Penal y Ciencias Penales, T. XXXII, Fasc. I, p. 5-11, donde destaca la importancia y ventajas del Derecho comparado como método de Política criminal. Dicho rol, es también recalcado por ZIPF (1979) 18. En el mismo sentido, más reciente, y en el marco de la integración europea también en nuestro ámbito, entre otros, Millitelo (2003) 47-67; Donini, Massimo (2003). "La Relación entre Derecho penal y política: método democrático y método científico". En Luis Arroyo Zapatero, Ulfrid Neumann, Adán Nieto Martín (Coords.), Critica y Justificación del Derecho penal en el Cambio de Siglo", Cuenca: Ediciones Universidad Castilla-La Mancha, pp. 91-94. Muñoz Conde Francisco (1975). Introducción al Derecho Penal, Barcelona: Bosch, pp. 185-187.

28 Ya antes, y en términos casi idénticos, JIMÉNEZ DE Asúa la calificó como "corolario de la dogmática". JIMÉNEZ de Asúa (1977) 175.

29) Fernández Carrasquilla, Juan (2002). Derecho Penal Liberal de hoy. Introducción a la dogmática axiológica jurídico penal, Bogotá: Ed. Jurídicas Gustavo Bańiz, pp. 225-226. 
plataforma marxista, propone que la política criminal debe erigirse como un instrumento al servicio de la transformación social ${ }^{30}$. De lo que se ha venido esbozando ya puede comprobarse aquello en que la doctrina es unánime: no existe hasta ahora claridad conceptual respecto de la disciplina en comento ${ }^{31}$.

Se ha de señalar además, y por último, que de los intentos "conceptualizadores" ya referidos, puede arribarse a otros más bien de carácter incierto (con la carga paradójica que ello implica si de lo que se habla es de la concreción de un concepto). Así, pueden encontrarse definiciones que ya no hablan de ciencia sino más bien de "arte", cuestión que, en mi opinión, antes que resolver la problemática planteada, pretenden superarla por vía de la evasión, construyéndose de dicha manera nociones más bien evanescentes, vaporosas. Concepciones de deslindes tan amplios como la volatilidad de sus marcas.

Así, en esta línea, por ejemplo, Schüler-Springorum la califica como "arte de lo posible" 32 o en Espańa Beristain Ipiña que la considera, al unísono, como ciencia y arte de aquello que es posible y deseable en el dominio de la criminalidad $^{33}$. Ya antes, Jiménez de Asúa, se había decantado por un concepto semejante, con la clara intención, eso sí, de marcar distancias con su primera postura sobre este punto, en el que calificaba a la política criminal como una ciencia. El propio autor posteriormente reconoce ello como un error, fundado en la influencia alemana muy próxima a él en ese entonces, de ahí que, con la intención referida, remarcara que esta es: “...más exactamente, un arte"34.

Es bueno seńalar que en estas líneas, evidentemente, no se pretende consolidar un concepto, sino más bien, se trata de un intento por echar algunas luces

Esta herramienta debería también incorporar como labor, auxiliar al movimiento obrero en su lucha contra la injusticia estructural del capitalismo, y con ello poder alcanzar las "grandes reformas sociales e institucionales para el desarrollo de la igualdad, de la democracia, de las formas de vida comunitarias y civiles alternativas y más humanas, y del contrapoder proletario, en vista de la transformación radical y de la superación de las relaciones sociales de producción capitalista". Baratta, Alessandro (1978). "Criminología Crítica y Política Penal Alternativa”. Revue Internationale de Droit Pénal, No 1, p. 50. Además, Baratta, Alessandro (1998). "Democracia, Dogmática, y Criminología: Cuestiones Epistemológicas y Políticas de las Ciencias Penales Contemporáneas", traducción de Ana Sabadell. En Augusto Sánchez y Venus Armenta (Coords.), Politica criminal y Sociología Jurídica, Ciudad de México: UNAM, pp. 182-188, haciendo este planteamiento específicamente respecto de América Latina. Entiendo en el mismo sentido la posición de Bergalli, Roberto (1982). "Observaciones críticas a las reformas penales tradicionales". En AA.VV., Politica criminal y reforma del derecho penal, Bogota: Temis, pp. 255-256, y de De Sola Dueñas, Ángel (1983). "Política Social y Política Criminal”. En Bergalli, R. y Bustos, J. (Dirs.), El Pensamiento Criminológico II, Barcelona: Península, pp. 245-263.

Desde una visión optimista de la polémica relativa a la confusión conceptual. CARrasQuiLLA, Juan (1984) VII-VIII. SCHÜLER-SPRINGORUM (1989) 28.

"Science et art de ce qui est posible et desiderable dans le domaine de la criminalité". BerisTAIN IPIŃA, Antonio (1999). "Hoy y mañana de la Política Criminal protectora y promotora de los Valores Humanos. (La paz desde la Victimología)". En AA.VV, Politica Criminal comparada, hoy y mañana, Madrid: CDJ, p. 18. JiMÉNEZ DE Asúa (1977) 175. 
sobre este tema en lo concerniente a establecer una plataforma desde donde comprenderle mejor. En dicha dirección me parece aconsejable que el primer paso que se dé, en pro de lograr cierta claridad en el análisis, pase necesariamente por, primero que todo, poner sobre la mesa de manera explícita, la distinción "formal" entre política criminal como actividad del Estado y aquella actividad científica que tiene por objeto el estudio de esa actividad estatal ${ }^{35}$. Es así como, esta diferenciación es precisamente un aspecto de la problemática sobre la cual se tiene al menos cierta claridad, razón por lo que parece un buen punto de apoyo para emprender las tareas de acercamiento a su rol en el sistema penal actual.

\section{2) POLÍTICA CRIMINAL COMO MANIFESTACIÓN DE PODER Y COMO MANIFESTACIÓN DE SABER: UN DISTINGO NECESARIO}

Así las cosas, se debe poner sobre la mesa de manera explícita y manifiesta la distinción "formal" entre política criminal como actividad del Estado y aquella actividad científica que tiene por objeto el estudio de esa actividad estatal ${ }^{36}$. Distingo primordial, siempre y cuando no se pierda de vista su carácter "no material" y se le considere como un reconocimiento de elementos distintos, pero no distantes, vinculados e interactuantes que la conforman y que es la manera en que aquí se le entiende.

Esto es, una distinción, mas no separación, que nos encamine ya en dirección de ese complejo núcleo de articulaciones dialécticas entre política y ciencias penales, que en su tiempo, y en uno de sus múltiples aspectos, ya nos intentara enseñar el maestro Baratta: “...toda esfera de la experiencia colectiva e individual resulta relevante para la forma y el contenido que adquiere la política; pero la política no es un objetivo en sí mismo y tampoco resulta ser una forma de conocer la realidad. En otras palabras, la política no es saber, pero se establece una relación funcional entre la producción y distribución del saber y la política" ${ }^{37}$.

Sin perjuicio de que no siempre se tenga en consideración de la manera que aquí se plantea, la distinción entre política criminal como actividad del Estado y como actividad científica, es un aspecto de la problemática, al menos desde el punto de vista clasificatorio, que sirve como una suerte de pivote sobre el cual

Distingo relevante pues, como seńala Baratta: “...toda esfera de la experiencia colectiva e individual resulta relevante para la forma y el contenido que adquiere la política; pero la política no es un objetivo en sí mismo y tampoco resulta ser una forma de conocer la realidad. En otras palabras, la política no es saber, pero se establece una relación funcional entre la producción y distribución del saber y la política". BaratTa (1998) 168-169.

En este sentido, Berdugo Gómez de la Torre, I.; Arroyo Zapatero, L.; Ferré Olivé, J. C.; García Rivas, N.; Serrano Piedecasas, J. R.; Terradillos Basoco, J. Ma (2004). Curso de Derecho Penal, Parte General, Barcelona: Ediciones Experiencia, p. 134. En contra de esta mayoritariamente aceptada distinción, Polaino Navarrete, Miguel (2004). Derecho Penal Parte General: Fundamentos Cientificos del Derecho Penal, Tomo I, Barcelona: Bosch, p. 60, quien califica a la Política criminal teórica como: "mera ilusión". 
existe un alto grado de concordia doctrinal, siendo esta otra razón por la que parece un buen punto de apoyo para emprender las tareas de acercamiento ${ }^{38}$.

\section{(2.1) LA POLÍTICA CRIMINAL COMO MANIFESTACIÓN DE PODER}

La política criminal como "manifestación de poder", puede entenderse como aquella enmarcada en la amplia gama de políticas públicas que el Estado debe (o debería) desarrollar para lograr sus objetivos, que en caso de la parcela criminal, está referida al cómo enfrentar el problema delictivo. Esto es, establecidos los objetivos del Estado en este campo, este ha de elaborar racionalmente la estrategia que vaya de acuerdo a la consecución de los mismos. Pues bien, desde esta perspectiva, las aproximaciones al concepto de política criminal pueden manifestarse provenientes desde una plataforma solo jurídico penal o desde una concepción social del delito ${ }^{39}$, siendo esta última la que se tendrá en consideración para los efectos de este trabajo ${ }^{40}$. En este mismo sentido ${ }^{41}$ señalaré solo dos

Distinción doctrinal ya bastante difundida, aunque con ligeras variantes terminológicas. Así, por ejemplo, se diferencia entre "ciencia politicocriminal y política criminal aplicada", "política criminal teórica y praxis politicocriminal", "actividad del Estado y actividad científica", "enfoque científico y práctica" o, en peculiar distinción, entre "POLÍTICA CRIMINAL con mayúscula y política criminal con minúsculas". Véase a modo de ejemplo y respectivamente: Zipf (1979) 18 y ss; Silva Sánchez, Jesús (2000). Politica Criminal y Persona, Buenos Aires: Ad-Hoc, pp. 21-24 y Silva Sánchez, Jesús (1999) "Reflexiones sobre las Bases de la Política Criminal". En Cerezo, J., Suárez, R., Beristain, A., Romeo, C., (Editores), El Nuevo Código Penal: Presupuestos y Fundamentos, Granada: Comares, pp. 212-213; Berdugo; Arroyo; Ferré; García; Serrano; Terradillos (2004) 134; Kaiser (1983) 60; Borja (2003) 22 23, y Borja (2003a) pp.130-131; Díaz-Aranda, Enrique (2006). Teoría del Delito, México: Straf, pp. 8-9.

39 Para otra perspectiva ZIPF (1979) 2-4. Para diversas definiciones, por ejemplo Beristain (1999) 13-23; Serrano (1980) 616-619.

i0 Según BoRJA JiMÉNEZ, optar por una u otra no tendría mayor relevancia dado que, para él, no se trata más que de un "desacuerdo terminológico, solucionable según su opinión, escribiendo "social" donde dice "criminal" en la acepción política de la disciplina y reservando el término "Política criminal" solo para aquella que se encarga del "estudio de la reacción al delito". BORJA (2003) 146-147.

41 Así, se le define como: "Aquel conjunto de medidas y criterios de carácter jurídico, social, educativo, económico y de índole similar, establecidos por los poderes públicos para prevenir y reaccionar frente al fenómeno criminal, con el fin de mantener bajo límites tolerables los indices de criminalidad en una determinada sociedad". BorJa (2003) 148 y Borja (2003a) 23. Barletta-Caldarera la señala como: "Conjunto de actividades del poder legislativo, ejecutivo y judicial que, partiendo del estudio de las causas biológicas, ambientales y utilitarias del delito, apuntan a la individualización de los instrumentos idóneos para la contención del crimen, mediante la eliminación, si es posible, de las causas o, en todo caso, reduciendo su incidencia". Barletta-Caldarera, Giacomo (1978). "Política Criminal y Derecho Penal". Revue Internationale de Droit Pénal, № 1, p. 71. En este sentido además Beristain (1999) 18-19; Bustos, Juan / Hormazábal, Hernán (2004). Nuevo Sistema de Derecho Penal, Madrid: Trotta, p. 25 y ss.; Luzón Peña, Diego-Manuel (2004). Curso de Derecho Penal, Parte General, Tomo I, Madrid: Editorial Universitas, p. 98 y ss; Quintero Olivares, Gonzalo (2005). Parte General del Derecho Penal, Navarra: Aranzadi, p. 201 y ss; Muñoz Conde, Francisco; García Aran, Mercedes (2004). Derecho Penal, Parte General, Valencia: Tirant lo Blanch, p.193; Serrano-Piedecasas, José Ramón (2001) "El Conoci- 
conceptos, por considerar que contemplan los elementos básicos de la definición del objeto analizado.

Así, Délmas-Marty la indica como aquel: "conjunto de métodos con los que el cuerpo social organiza las respuestas al fenómeno criminal" 42 y desde otra instancia, el Consejo de Europa la definió en su momento como aquel: "Conjunto de medidas, de carácter penal o no, tendientes a asegurar la protección de la sociedad contra la criminalidad, a regular debidamente el tratamiento de los delincuentes y a garantizar los derechos de las víctimas" ${ }^{33}$. Así, puedo manifestar mi acuerdo con Bustos Ramírez, cuando respecto de la política criminal como actividad estatal, la califica como "un poder de definición de un conflicto como delito que ejerce en exclusiva el Estado" 44 y desde él plantearnos esta como una de las políticas del Estado que escindida en dos planos decide por un lado qué conflictos se criminalizan, y por el otro, determina el conjunto de medidas para enfrentarse preventivamente a dicho fenómeno.

Ahora bien, la política criminal no puede ser comprendida solo como una tarea de criminalización, sino también de descriminalización cuando ello resulte adecuado a sus fines, y también determinará, lo que es aún más importante, cuando deban ser otros los instrumentos de control social aptos para enfrentar el problema ${ }^{45}$. En este sentido, la política criminal no será solo el sector donde se determine crimen y castigo ${ }^{46}$, sino que su axial función será la prevención. Todo lo cual se desarrollará en un Estado Democrático de Derecho, lo que implica necesariamente el respeto a los principios y valores que lo sustentan, desde una perspectiva material ${ }^{47}$.

miento Científico del Derecho Penal". En Nieto Martín, Adán (editor), Homenaje al doctor Marino Barbero Santos, Cuenca: Ediciones de la Universidad de Castilla-La Mancha y Ediciones Universidad de Salamanca, pp. 669-670; Cuervo Pontón, Luis (1988). Politica Criminal, Bogotá: Universidad Javeriana, pp. 83-85, Langle, (1927) 82; NovoA Monrreal, Eduardo (1977). La evolución del Derecho Penal en el presente Siglo, Caracas: Editorial Jurídica Venezolana, pp. 64-65; Vassalli, Giuliano (1978). "Política Criminal y Derecho Penal". Revue Internationale de Droit Pénal, № 1, p. 379.

42 Délmas-Marty (1986) 19.

43 Citado por Beristain (1999) 18.

44 Bustos / Hormazábal (2004) 25. En el mismo sentido, entre otros: Binder, (1997) 42; Mir Puig, Santiago (2006). Estado, Pena y Delito, Montevideo-Buenos Aires; Editorial B de F, pp. 3-12; Quintero (2004) 39; Berdugo; Arroyo; Ferré; García; Serrano; TeRradillos (2004) 134; López-Rey (1978) 347; Zipf (1979) 18 y ss; Silva (2000) 212-213; Kaiser (1983) 60; BorJa (2003) 22-23. y Borja (2003a) 130-131. En este sentido ZúŃIGA (2001) 154.

46 "Como toda arma peligrosa, la pena preventiva ha de someterse a un control riguroso. Un Estado democrático ha de evitar que se convierta en un fin en sí mismo o al servicio de intereses que no convenientes para la mayoría de los ciudadanos, o que desconozca los límites que debe respetar frente a toda minoría y todo individuo." Mir (1994) 37.

47 Sobre este concepto Ferrajoli, Luigi (1999). Derechos y Garantias, La ley del más débil, Traducción ANDRÉs IBÁŃEZ, Perfecto, Madrid: Trotta, p. 51. 


\section{(2.2) LA POLÍTICA CRIMINAL COMO MANIFESTACIÓN DE SABER}

Respecto de la política criminal como "manifestación de saber", esta requiere situarse desde el plano de la relación "ciencia/objeto de estudio". Así, esa actividad estatal, será analizada, sistematizada y criticada desde el ámbito científico, de forma que puede aportar desde allí no solo a la consecución de los objetivos, sino también al establecimiento de los mismos, de manera que, y en palabras de Silva Sánchez esta: "...aparece construida por un conjunto de principios teóricos que habrían de dotar de una base racional a la referida praxis" 48 .

Así pues, la política criminal en cuanto "actividad cientifica" puede señalarse, en estrecho resumen, que las dificultades se presentarán principalmente en cuanto esta tenga la aspiración en ser calificada como ciencia independiente ${ }^{49}$, sin perjuicio de pasar no pocos apuros incluso a la hora de precisar su objeto de estudio. "Es una disciplina que hasta ahora no está dotada de un método científico, de racionalidad, de claridad en el objeto y en el método" 50 .

Ciertamente, es posible establecer con claridad que esta es un sector del conocimiento marcado por su interdisciplinariedad, característica que siéndole reconocida por unos como su mayor virtud, es a la vez y precisamente para otros su principal flanco de críticas, si se tiene en cuenta la pretensión emancipadora de los saberes que la conforman. Dicho de otra manera, la crítica de los primeros encuentra fundamento en que la política criminal no debe ser solo la "acumulación" de las ciencias que la componen, sino la "integración" de dichos

Silva (1999) 213 (cursiva en el original). Crítico sobre la capacidad de rendimiento de la política criminal, denominándola incluso "mera especulación moral" Gómez Benítez, José Manuel (2001). Estudios Penales, Madrid: Colex, pp. 9-14. Zaffaroni, más cáustico, en la línea de la criminología crítica, señala sobre el punto: "Es tan obvio que el derecho penal no puede permanecer separado de la política que, para evitar el escándalo de semejante negación, se inventó un sustituto que da la impresión de mantener la interdisciplinariedad. Para eso se usó la política criminal: se apeló a la ya citada confusión entre los planos del ser y el deber ser, se inventó una sociedad que no existe, se dio por presupuesto la función preventiva general de la pena y, como resultado de eso se alucinó una política que se pretende que funciona como nada funciona en la práctica. Eso solo sirve para que los políticos sancionen las leyes con falsos fines manifiestos (pretendiendo que combaten lo que no combaten) y para aumentar el ámbito de arbitrariedad criminalizante y el de vigilancia policial" ZAFFAroni; Aliaga; Slokar (2005) 126. Para una visión desde la criminología crítica Baratta (1978) 43-55.

44) Respecto de los partidarios de dicha autonomía encontramos, en palabras de BaIGúN, "Especialmente a Von Liszt y una lista interminable de sus seguidores". BAIGÚN (1978) 31, entre ellos ZIPF (1979) 14. En contra, por ejemplo, JIMÉNEZ DE AsúA, que retractándose de antes haberla calificado como ciencia, atendida la proximidad de su formación alemana, señalaba: "La Política criminal no puede calificarse como ciencia autónoma... si desentrańamos lo que es, veremos que no se trata de una rama científica. Es un método de trabajo, o, más exactamente, un arte." JimÉnez de AsúA (1977) 175. En semejante sentido ANTÓN ONECA seńalaba; "O sea que dogmática jurídico-penal y política criminal se superponen y complementan, siendo nos disciplinas separadas, sino más bien zonas o aspectos de la ciencia penal." ANTón (1986) 25, además Cerezo (2004) 88-90. 
conocimientos en un todo sistémico y coherente dirigido a un objeto de estudio mediante un método claro, sin que hasta ahora se haya indubitadamente logrado tal objetivo ${ }^{51}$. De tal forma que todavía no es cuestión pacífica dar a la política criminal ese rango de "disciplina científica autónoma" que algunos le reclaman como imprescindible ${ }^{52}$.

Ahora bien, afirmar lo anterior no implica, de ningún modo, negar su incuestionable importancia, "simplemente hay que ser conscientes de que la forma en que nos aporta su análisis de la realidad que examina es distinta" 53 . Esa tarea, por tanto, que la política criminal realiza desde la perspectiva de la "actividad científica" es mayoritariamente encasillada dentro del ámbito de las "ciencias penales" 54 , lugar desde el cual, como ya se ha dicho, llevará a cabo su tarea de

51 "No obstante, todos estaremos de acuerdo en que hasta ahora no existe coincidencia en cuanto a su naturaleza ni menos en cuanto concierne a sus fronteras". BAIGÚN (1978) 31. En relación con la independencia conceptual de la política criminal respecto de la dogmática y la criminología, ZIPF (1979) 18. Sin perjuicio de que en ella solo se esboce un concepto negativo, sin que se logre precisar "qué es" la política criminal. Recogiendo el reparo DéLMASMarty, que también marca dicha independencia, señala: "Manifestar, empero, lo que no es la política criminal, no es suficiente, sin duda, para describir lo que es, y menos aún para captar su unidad a través de la diversidad...” Délmas-Marty (1986) 20. Bustos Ramírez destaca que con el surgimiento de la criminología crítica tiende a confundirse esta con la Política criminal, "...en tanto que ambas estudiarían la legislación desde el punto de vista de los fines del Estado y, además, harían la crítica de ellos para la reforma del derecho penal en general." Bustos Ramírez, Juan (1983) "La Criminología", en Bergalli / Bustos (Dirs) 25, en el mismo sentido ZafFARONI (1993) 20. Sin perjuicio de ello, tal confusión existía ya con anterioridad. Gráfico sobre el punto resulta lo comentado por López ReY sobre la obra "Kriminalpolitik" de MEzger, senalando que este: "...identifica en no poco política criminal y criminología, hasta el punto de que Rodríguez Muńoz, traductor de la obra, propuso que en el texto español el título fuera Criminología. Tal yuxtaposición ha oscurecido la separación necesaria entre criminología y política criminal." López-ReY (1978) 341.

52 Respecto de la evolución del concepto Política Criminal entre otros Von LiszT (1914) 42-85; Jiménez de Asúa (1977) 170-175; Langle, (1927) 27-41; Roxin, Claus (2000). La Evolución de la Política Criminal, el Derecho Penal y el Proceso Penal, Valencia: Tirant lo Blanch; Bustos Ramírez, Juan (1986). Introducción al Derecho Penal, Bogotá: Temis, pp. 190-226 y Bustos Ramírez, Juan (1985) "Política Criminal y Dogmática". En Bergalli, R. I Bustos, J. (Dirs) El Poder penal del Estado, Buenos Aires: Depalma, pp.123 y ss.; Mir (2006) 13-34; López-Rey (1978) 340-348 y López-Rey (1985). Compendio de Criminología y Politica Criminal, Madrid: Tecnos, pp. 147-152; ZúñIga (2001) 67-130; BorJa (2003a) 121 y ss; Moreno Hernández, Moisés (2003). "Vinculaciones entre Dogmática Penal y Política Criminal". En Ontiveros Alonso, Miguel y Peláez Ferrusca, Mercedes (Coords). La Influencia de la Ciencia Penal Alemana en Iberoamérica, Tomo I, México: INACIPE, p. 359 y ss. Respecto de la introducción y desarrollo de la Política criminal en América Latina. DeL Olmo, Rosa (1981). América Latina y su Criminología, Ciudad de México: Siglo XXI, pp. 179-196.

53 Borja Jiménez, Emiliano (2002). Ensayos de Derecho Penal y Politica Criminal, San José: Editorial Jurídica Continental, p. 210.

54 En este sentido, entre otros, Jescheck, Hans y Weigend, Thomas (2002). Tratado de Derecho penal parte General. Traducción de Olmedo Cardenete, Miguel, Granada: Comares, pp. 46-50; Bustos Ramírez, Juan / Hormazábal. Malarée, Hernán (1999). Lecciones de Derecho Penal, Parte General, Madrid: Trotta, pp. 29-34; Mir Puig, Santiago (2005). Derecho Penal, Parte General, Barcelona: Reppertor, p. 60; Luzón (2004) 98-99; QuiNtero (2005) 201-216; Muñoz, García (2004) 194; Berdugo; Arroyo; Ferré; García; 
estudio y análisis tanto de los objetivos que se pretenden alcanzar como de los principios a los que, tanto medios como fines, deben estar sometidos.

En dicha función habrá de sistematizar las herramientas, no solo jurídicas claro está, en pro de conseguir los fines que se hayan determinado, además de dedicarse al examen en las distintas etapas del sistema penal en relación con los objetivos que se hayan establecido por las agencias estatales correspondientes ${ }^{55}$, buscando concretar, o al menos intentar, poner en la práctica aquello que desde las normas y directrices se proclama. Por ello resulta importante no perder de vista al sistema penal precisamente como eso, un sistema, como un "todo" que ha de mantener necesariamente, para su buen funcionamiento, coherencia entre sus distintos subsistemas. Respecto de la política criminal establecida por el Estado dice Binder "...la política criminal es la que va a plantear los grandes objetivos de todo el sistema y cada uno de los subsistemas debe ser coherente con la preservación de esos objetivos" 56 de ahí que resulte trascendente destacar que si la política criminal como actividad del Estado se manifiesta en distintos niveles, ésta misma, desde la perspectiva que ahora se comenta, ha de desarrollar su tarea también en esos diversos planos ${ }^{57}$.

Serrano; Terradillos (2004) 134; Núnéz Barbero, Ruperto (1982) "Derecho Penal y Política Criminal". En AA.VV., Estudios Penales, Libro Homenaje al Profesor José Antón Oneca, Salamanca: Ediciones Universidad de Salamanca, p. 413; Ortiz de Urbina Gimeno, Ińigo (2003). "Roxin y la Dogmática político-criminalmente Orientada". En Ontiveros Alonso, Miguel y Peláez Ferrusca Mercedes (coords) La Influencia de la Ciencia Penal Alemana en Iberoamérica, Tomo I, México: INACIPE, pp. 425-440; Vidaurri Aréchiga, Manuel (2003). "Criminología, Política Criminal y Sistema de Justicia Penal". En Ontiveros Alonso, Miguel y Peláez Ferrusca Mercedes (coords) La Influencia de la Ciencia Penal Alemana en Iberoamérica, Tomo I, México: INACIPE, pp. 390-391; Cuervo (1988) 83. En el mismo, sentido aunque puntualizándola como auxiliar, SiLVA SÁnCHez, Jesús (2002). Aproximación al Derecho Penal Contemporáneo, reimpresión, Barcelona: Bosch, p. 45.

Córdoba Roda, Juan (1978). "Evolución Política y derecho penal en España". Revue Internationale de Droit Pénal, No 1, p. 14.

Binder (1997) 26-28, y Binder, Alberto. (2004). Justicia Penal y Estado de Derecho, Buenos Aires: Ad Hoc, pp. 60-67.

57 En este sentido Berdugo; Arroyo; Ferré; García; Serrano; Terradillos (2004) 135, señalan: "La política criminal realiza, por tanto, una investigación cuyos resultados van dirigidos no solo al legislador, sino también al juez y a los restantes protagonistas de las distintas instancias de control, como la policía, el personal penitenciario, los trabajadores sociales, etc." Sobre este aspecto resulta particularmente relevante lo que dice relación con el proceso penal, que como se ha dicho, "es uno de los ámbitos básicos donde se realiza la política criminal". Bustos Ramírez, Juan (1997). "Política Criminal y Estado". En AA.VV., Estudios Juridicos Homenaje al Profesor José Casabó Ruiz, Vol. I, Valencia: Universidad de Valencia, p. 317; Bueno Arús, Francisco (1978). "Algunas consideraciones de la Política Criminal de nuestro tiempo". Revue Internationale de Droit Pénal, No 1, p. 118; Beristain (1999) 18-19; Barletta-Caldarera (1978) 72; Bricola, Franco (1978). "Política Criminal y Derecho penal". Revue Internationale de Droit Pénal, No 1, p. 111; CóRdoBa (1978) 141; Polaino Navarrete, Miguel (1988). Criminalidad Actual y Derecho Penal, Córdoba: Universidad de Córdoba, p. 24; Vassalli (1978) 387; Maier, Julio (1978). "Política Criminal y Derecho Procesal Penal". Revue Internationale de Droit Pénal, № 1. Además existe la interesante síntesis del aporte que desde esta perspectiva ha realizado el Profesor Maier. En Rusconi, Maximiliano (2005). "¿Un sistema de enjuiciamiento influido por la Política 
Estas funciones han sido catalogadas por Zúńiga Rodríguez en dos etapas ${ }^{58}$, que podrían caracterizarse como: una destinada al análisis y estudio compuesta por $^{59}$; 1) Estudio de la realidad del delito; 2) Estudios de los mecanismos de prevención del delito; 3) Crítica de la legislación Penal. Y la segunda referida al diseño y evaluación de la respuesta estatal, conformada por; 1) Diseño de un programa integral de política criminal, 2) Evaluación de la política criminal ${ }^{60}$.

Es así entonces como puede entenderse, en los términos que plantea Jescheck, que la política criminal: “...se fija en las causas del delito, intenta comprobar la eficacia de las sanciones empleadas por el derecho, pondera los límites donde el legislador puede extender el derecho penal para coartar lo menos posible el ámbito de libertad de los ciudadanos, discute cómo pueden configurarse correctamente los elementos de los tipos para corresponder a la realidad del delito y comprueba si el derecho penal material se haya configurado de tal forma que pueda ser verificado y realizado en el proceso penal" 61 .

\section{(2.3) SÍNTESIS: CONCEPTO DE TRABAJO}

En base a lo que se ha venido explicando, creo necesario distinguir a la política criminal como actividad del Estado de la actividad científica que adopta su mismo nombre. En consecuencia, puede entenderse que la política criminal está referida más bien a la estrategia que ha de desarrollar el Estado para mantener en límites razonables los delitos cometidos, esto es, que permitan la vida en sociedad. Pero, como esa actividad del Estado, en uno social y democrático

Criminal?". En AA.VV., Estudios sobre justicia penal: homenaje al Profesor Julio B. J. Maier, Buenos Aires: Editores del Puerto, pp. 431-448.

58 En parecido sentido, señala Núñez PAZ, que la Política Criminal debe intervenir en; la interpretación del Derecho Penal positivo, en la formación del sistema -dogmática-y en la determinación de la pena. Núńez PAZ, Miguel Ángel (2004). "Dogmática Penal y Política Criminal frente a la Reforma”. En Rosario Diego Díaz-Santos, Eduardo Fabián Caparrós, Carmen Rodríguez Gomez (Coords.), La reforma Penal a debate, Salamanca: AUSEJP, p. 16. Sobre la importancia de esta etapa ya se pronunciaba Von LiszT, destacándola en el concepto mismo de política criminal. Von Liszt (1914) 62.

60 ZúNigA (2001) 163-176. Al respecto Marc ANCEL establecía:"...una verdadera política criminal es un sistema coherente y racional de reacción antidelictiva. Por lo tanto cualquier comentario acerca de la Política criminal exige: una definición clara de sus objetivos y de los medios para alcanzarlos, una acción coherente y coordinada y, la utilización de los datos obtenidos y comprobados por las investigaciones empíricas acerca de la criminalidad y la justicia penal." AnCel, Marc, citado por Beristain (1999) 15-16.

61 JESCHECK / WEIGEND, (2002) 24. En este sentido LAZERGES señala: "...la política criminal es una reflexión epistemológica acerca del fenómeno criminal, una decodificación del fenómeno criminal y de los medios empleados para luchar contra los comportamientos desviados o delictivos..." citada por Beristain (1999) 14-15. Además, en el mismo sentido, entre otros: Borja (2003) 23; Kaiser (1983) 60; Serrano-Piedecasas (2001) 669-670; Cuervo (1988) 83-85, Langle, (1927) 82; Novoa (1977) 64-65; Berdugo; Arroyo; Ferré; García; Serrano; Terradillos (2004) 134-137. Desde una perspectiva criminológica BarbeRET, Rosemary (2000). "La Investigación Criminológica y la Política Criminal". Revista de Derecho Penal y Criminologia, No 2, pp. 221-222. 
de derecho, no puede ni debe ser pura represión autómata, es que requiere de la racionalidad necesaria para enfrentarse al fenómeno delictivo ${ }^{62}$, racionalidad que viene dada, precisamente, por la política criminal en su acepción multidisciplinaria de aproximación científica desde saberes diversos pero interconectados.

De ahí la importancia de ella en su segunda acepción, de ahí la importancia de determinar su función al interior del sistema penal, o al menos intentar marcar algunos deslindes, referido a esas distintas disciplinas que la conforman, destacando el rol estratégico y esencial de la política criminal.

\section{3) TRES VISIONES DEL ROL DE LA POLÍTICA CRIMINAL}

\section{(3.1) POLÍTICA CRIMINAL CON FUNCIÓN DE LEGE FERENDA}

Como ya antes se dijo, esta es una de las primeras funciones que le fueron asignadas a la política criminal. Durante mucho tiempo se le consideró casi en exclusivo objetivo y, por ello, separado del Derecho Penal. Es así como, y respecto de este primer punto, se manifiesta un trasfondo que conviene destacar, puesto que implica dar a la política criminal una perspectiva desconectada del Derecho Penal positivo y por lo mismo, fundamentalmente distinta pues, así planteada, ella no estará abocada sino solo a la culminación del proceso crítico, sin intervención en la aplicación del mismo ${ }^{63}$.

De manera que, desde una visión como esta se aparta a la política criminal del funcionamiento del sistema, dejándole como tarea no el Derecho penal del "presente", sino el del "futuro", de manera tal que lo que se obtiene por resultado es el distanciamiento de ambas concepciones. El Derecho Penal positivo y vigente no sería ámbito de la política criminal. Con rotunda claridad sobre esta perspectiva se muestra Sainz Cantero, quien señala: "De este modo se configura la política criminal y la Ciencia del Derecho Penal como disciplinas distintas y separadas. La primera, por su misma naturaleza, es una disciplina destinada al porvenir; la segunda es fundamentalmente una ciencia que está destinada al presente" 64 . Podría parangonarse la desconexión entre los objetivos político criminales y el derecho positivo, como equivalente a la distancia establecida entre la dogmática y la realidad. Con intención de superar dicha deficiente situación

62 De esta manera puedo aquí concordar con la doctora ZúńIGA cuando sintetiza, lo que aquí se viene seńalando, de la siguiente forma: "...de lo que se trata, y en ello va la sustantividad de la Política criminal, es de lograr resultados de efectividad en la prevención de la criminalidad, dentro de los cánones del respeto a los derecho fundamentales". ZúŃigA (2001) 131.

Así se señala: "Su ensamblaje con la Dogmática Penal no se traduce en actuaciones positivas "inmediatas" sobre el sistema, sino que se reduce a operar, como criterio de la fase "crítica", culminadora del proceso dogmático, pero apartada del ámbito del sistema positivo." QuiNTERO (2005) 204.

Sainz Cantero (1979) 93. En el mismo sentido, Calderón / Choclán (1999) 17-18; Cuello (1996) 43. 
se comenzó a trabajar con conceptos que fueran dirigidos a superar el problema de las distancias, esto es, "un puente".

\section{(3.2) POLÍTICA CRIMINAL COMO PUENTE ENTRE LA CRIMINOLOGÍA Y LA DOGMÁTICA JURÍDICO PENAL}

\section{(3.2.1) Evolución por asentamiento}

En relación con la segunda de las concepciones referidas, aquella que entiende a la política criminal como un "puente" entre la Criminología y la dogmática jurídico-penal, debe partirse diciendo que esta es, ciertamente, la posición doctrinal que más seguidores tiene ${ }^{65}$. Dicha visión mayoritaria, destaca la unión, mediante la política criminal, de las consideraciones de orden empírico ${ }^{66}$ y aquellas de tipo valorativas. Debe recordarse que dado el perfil evolutivo que se ha venido señalando, el hecho de que se entienda la política criminal como dedicada a la reforma del derecho penal no deviene en contradictorio que los mismos autores que sustenten la visión de "Lege Ferenda" opten también por admitir el concepto de "puente". En este sentido puede verse lo señalado por Maier cuando señala que la tarea de la política criminal puede resumirse según el itinerario histórico seguido por esta, expresando que ella: "funciona criticamente sobre los institutos jurídicos vigentes de la mano de los resultados que ellos han producido en la práctica concreta, en los hechos, y, a partir de allí, propone su reemplazo o modificación, según métodos racionales que pretenden tener firme fundamento en investigaciones empíricas..." 67.

Y es que si se tiene en consideración que el desarrollo de la política criminal es más proceso de extensión que de negación de conceptos anteriores, puede entenderse que posturas distintas logren reunirse en una misma metáfora, lo que además es una lógica explicación a que sea esta la postura mayoritaria.

Sin perjuicio de lo anterior, es bueno aclarar que la tratamos como posturas distintas, enmarcado en un desarrollo por asentamiento, ya que la visión de "puente" que aquí seńalamos, implica que la unión de lo empírico con lo valorativo no solo estará destinada a la sola reforma del derecho penal, sino también a su aplicación y con ello a su interpretación y crítica de las instituciones vigentes. Así, por ejemplo, en Alemania señala Arzt: "En el proceso legislativo, es decir, en la decisión acerca de si los viejos preceptos penales deben derogarse o deben crearse preceptos nuevos, así como también a la hora de proceder a la interpre-

\footnotetext{
65 García-Pablos de Molina, Antonio (2005). Introducción al Derecho Penal, Madrid: Editorial Universitaria Ramón Areces, p. 766.

66 Para una concreta enumeración de la utilidad de la investigación criminológica para la Política Criminal, Barberet (2000) 222-225.

67 Maier, Julio (1985). "Balance y Propuesta del Enjuiciamiento Penal del Siglo XX". En Bustos, Juan / Bergalli, Roberto, (Dirs) El Poder penal del Estado, Buenos Aires: Depalma, p. 279 (cursiva en el original).
} 
tación de los preceptos legales vigentes deben entrar en juego consideraciones político-criminales" 68 .

\section{(3.2.2) La función del puente}

Es evidente que con la metáfora del "puente" lo que se está necesariamente asumiendo es la separación entre política criminal, dogmática penal y criminología (y es que solo lo separado podría necesitar de un puente) esto es, que la política criminal no es parte ni de la segunda ni de la tercera de las recién mencionadas, cuestión que no resulta baladí, dada la histórica discusión sobre este punto. Esto es, con la visión tridimensional de la cuestión que se ha venido consolidando, se da por superada la postura de la política criminal como "criminología aplicada" ${ }^{69}$ y lo mismo debería ocurrir con aquella que la reconoce como parte de la Dogmática penal, aunque en menor medida según mi opinión ${ }^{70}$. Criticando lo primero, seńala Cerezo Mir: "La política criminal no puede formar parte de la Criminología porque la crítica y la propuesta de reforma del Derecho positivo no se puede realizar sin un conocimiento previo, profundo, del mismo y este conocimiento es ajeno al objeto de la Criminología"71.

Asertos de este tipo parecen ya fuertemente consolidados, cuestión que no ocurre de la misma manera con lo segundo. Me refiero a que la pertenencia de la política criminal a la Dogmática penal es aún considerablemente fuerte, lo que se realiza por la doctrina directamente, vía invocación de Antón Oneca ${ }^{72}$, o, incorporando a la política criminal como corolario de la dogmática en su versión crítica $^{73}$. De modo que las voces que hablan de la política criminal como parte de la Dogmática penal no pueden considerarse "silentes", aunque, quizá, sí hayan bajado la voz.

Roxin, Claus; Arzt, Günther, Tredemann Klaus (1989). Introducción al Derecho Penal y al Derecho Penal Procesal, Barcelona: Ariel Derecho, p. 118. En el mismo sentido Mir Puig, Santiago (2002). Introducción a las bases del Derecho Penal, 2a edición reimpresa, Montevideo: Editorial B de F, pp. 299-300.

Sobre este punto entre otros: SCHÜler-SPRINGORUM (1989) 8-11; ZAFFARONI (1993) 20-21.

70 En este sentido dice NúŃEz Paz: "Se sostiene que la Política Criminal debe situarse desde dentro del sistema, de aquí que se afirme que si bien la Política Criminal ha logrado una delimitación aceptable respecto a la Criminología, corra peligro de ser absorbida por el Derecho penal." NúNEZ (2004) 16. Cerezo (2004) 89.

72 Calderón / Choclán (1999) 17-18; Cerezo (2004) 89. Romeo (1997) 13; Serrano Gómez (1980) 634. Rodríguez Devesa, en cambio, matiza considerando que la política criminal forma parte a la vez de la criminología y del derecho penal, lo que solo dependerá de si se trata de aquella parte de la Política criminal que trata de "problemas utilitarios que presenta la realidad en la lucha contra el delito" o de aquella que está "abocada a buscar las soluciones legislativas más adecuadas a situaciones concretas" como parte de la criminología en el primer caso, y del Derecho penal el segundo, siendo este último, por cierto, también el momento para citar a Antón Oneca Rodríguez / Serrano (1994) 18. MuÑoz (1975) 185-187, siguiendo a JiMÉNEZ DE Asúa (1977) 175. 
De todo ello pueden advertirse dificultades no meramente de orden clasificatorio, sino problemas de calado real y práctico. Una de ellas, en mi opinión la de mayor alcance, es la que Baratta había agudamente puesto de manifiesto, respecto de la barrera con que choca una política criminal científica en el intento de aplicar el conocimiento proveniente de la criminología a una política criminal práctica. Me refiero a que desde una perspectiva que incluya a la política criminal dentro de la dogmática penal, es más factible caer en el error reduccionista de poner atención solo a los aspectos de la criminología que puedan ser más directa y fácilmente traducidas a medidas de carácter penal ${ }^{74}$, poniendo a la criminología y sus aportes al servicio de una política meramente penal ${ }^{75}$, lo que evidentemente redunda en una infravaloración de las potencialidades de la criminología y en un déficit de las medidas político criminales de carácter integral $^{76}$.

Volviendo al punto de la visión tridimensional de la ciencia penal, se debe decir que en esta cada una de las disciplinas mencionadas tiene un centro de interés asignado, así las cosas, sin perder de vista las limitaciones de cualquier simplificación, en palabras de Mir Puig cabría expresar que: "la Dogmática jurídicopenal se ocupa del Derecho penal como norma, la Criminología como hecho, y la política criminal como valor"77. De la misma opinión es García-Pablos, quien se refiere a lo expuesto en los siguientes términos: "Esto es, que Criminología, Politica Criminal y Derecho Penal representan tres momentos inescindibles de la respuesta social al problema del crimen: el momento explicativo-empírico (Cri-

En este sentido crítico, entiendo a ZaFFARONI cuando se refiere a las vinculaciones de la criminología y la Política criminal: "Desde que abandonamos el punto de vista "causal" en este limitado sentido, nos damos cuenta de que el hilo conductor de la criminología es el poder y, por ende, la política, en lo cual coincidimos con los críticos centrales (PAVArini), de modo que no tendría sentido distinguir entre "criminologia" y "politica criminal", pues esta ya no podria ser definida como la politica estatal de lucha contra el crimen, sino que pasaría a ser la ideologia politica que orienta al control social punitivo". ZAFFARONI (1993) 21.

75 Ello porque, según Baratta, el jurista penal tiene puesta su mira "casi exclusivamente el momento represivo (politica penal en sentido estricto)". Baratta, Alessandro (1982). "Criminología y Dogmática penal. Pasado y futuro del modelo integral de la ciencia penal". En AA.VV., Politica criminal y reforma del Derecho penal, Bogotá: Temis, p. 55.

76 A mayor abundamiento, sobre este punto indica BaratTA: "Esto explica también la predilección general de los juristas por la denominada "criminología multifactorial", es decir, por aquella criminología que, manteniendo todos los equívocos relacionados con el paradigma etiológico positivista, renunció al mismo tiempo a seguir contextos teóricos amplios, como lo hiciera la criminología liberal en sus mejores días. Este carácter ateórico y ecléctico de la criminología multifactorial, que pone evidentemente en duda su carácter científico, es explicable a partir del cortocircuito mediante el cual la criminología fue reducida a ciencia auxiliar de la política penal; perdía con ello su función explicativa de las relaciones macrosociales del fenómeno de la criminalidad..." Baratta (1982) 55.

77 Sobre ello Mir Puig señala: "Se trata de un planteamiento sin duda excesivamente esquemático y posiblemente incorrecto si se entiende al pie de la letra, puesto que ninguna disciplina que estudie el Derecho penal puede dejar de tener en cuenta que el mismo es siempre y a un tiempo norma, hecho y valor; pero puede resultar pedagógico si, hecha esta advertencia, se pretende únicamente seńalar que cada una dé las tres dimensiones del Derecho indicadas constituye el centro de interés respectivo de las tres disciplinas que estudian al Derecho penal" Mir (2005) 60. 
minologia), el decisional (Politica Criminal) y el instrumental (Derecho Penal)." Para concluir sentenciado: "Saber empírico y saber normativo no pueden "seguir sus caminos" distanciados" 78 .

$\mathrm{Y}$ es que es precisamente ello lo que motiva la aproximación a los terrenos de la política criminal, el intento por acercar realidad y dogmática penal ${ }^{79}$. Ya desde tiempos de Von Liszt se criticaba la fisura existente entre ambas. Sobre ello señalaba en su Programa de Marburgo: "Desde hace decenios, los representantes más significativos de la ciencia del Derecho penal se han ido distanciando de la vida real. La ciencia del Derecho penal ha disipado sus esfuerzos en luchas infructuosas y se ha implicado en trabajos sobre ideas puramente abstractas, en lo que no percibía lo que acontecía en el exterior. Creía tener en sus manos, como antes, las riendas del poder, mientras la vida real había dejado de preocuparse de ella mucho tiempo atrás" 80 . De ahí la evocación del "puente", la necesidad de unir lo dogmático a lo concreto, manifestado por Von Liszt en la "idea del fin del derecho penal".

\section{(3.3) LA POLÍTICA CRIMINAL DESDE LAS BASES DEL SISTEMA PENAL}

Con ello llegamos a la tercera de las posturas referidas, esto es, aquella que incorpora los criterios político criminales en las bases mismas del sistema ${ }^{81}$, no ya únicamente para el derecho penal del futuro, ni solo para vincular la dogmática a la realidad, sino para, en permanente tendencia de la política criminal, ir un paso más adelante y buscar una síntesis entre dogmática y política criminal ${ }^{82}$, "Es necesario romper las barreras de la incomunicación de la Ciencia del Derecho y las necesidades de la realidad social, debiendo ser estas formuladas por una Politica Criminal crítica, construida sobre bases criminológicas" 83 .

Por ello en este punto surge la necesidad de encontrar en la política criminal "una disciplina valorativa" 84 encargada de establecer y aplicar las herra-

García-Pablos (2005) 767.

En este sentido Göppinger (1975) 21; Hormazábal Malarée, Hernán (2006). Bien Jurídico y Estado Social y Democrático de Derecho (El objeto protegido por la norma penal), Santiago: LexisNexis, $2^{a}$ edición, pp. 78-81.

Von Liszr, Franz (1995). La Idea del Fin en el Derecho Penal, Programa de la Universidad de Marburgo 1882. Traducción Pérez, Carlos, Granada: Comares, p. 95.

"En efecto, el conocimiento de las exigencias propias de la lucha contra el delito -esto es: de la Política Criminal basada en la Criminología- es preciso tanto para una elaboración científico-social de los conceptos penales, como para una aplicación realista de la ley." Mir (2002) 300. Sin perjuicio de lo anterior, debe señalarse que no pocas veces ello queda más en aspiración que en realidad político criminal. En el mismo sentido Durán MigLiard, Mario (2006). Introducción a la Ciencia Jurídico-Penal Contemporánea, Santiago: Ediciones Jurídicas de Santiago de Chile, pp. 48-51.

García-PABLOS (2005) 765.

García-Pablos (2005) 765.

ZIPF señala: "en cuanto se trata de fijar y realizar metas político criminales, es necesario adoptar decisiones valorativas. Estas decisiones valorativas no se derivan del resultado de un examen empírico (es decir, del ser), sino que han de obtenerse a partir de baremos normati- 
mientas idóneas para lograr su fin, esto es, la prevención de la criminalidad ${ }^{85}$, contemporizando lo científico social y lo normativo ${ }^{86}$, de modo de no suprimir una disciplina por otra ${ }^{87}$, sin contraponerlas, sino complementarlas ${ }^{88}$ y de dicha forma mantenerlas en continua colaboración en pro de un fin común, logrando enfrentarse al problema delictivo dentro de los márgenes de la forma de Estado a la que pertenece ${ }^{89}$, pero asentada sobre bases no meramente "intuitivas" de lo social $^{90}$, sino científicas y contrastables ${ }^{91}$.

Señala García-Pablos: "La Ciencia del Derecho no puede volver la espalda a la realidad social ni a las otras parcelas del saber, aislándose en sus conceptos, técnicas y valoraciones. Pero tampoco puede disolverse en una Sociología, olvidando sus particulares necesidades y el específico campo de lo normativo al que

vos. Lo que debe ser no se deduce de lo que es, sino de la decisión en favor de una determinada posibilidad de configuración". ZIPF (1979) 9. ZÚÑIGA (2001) 159-163.

86 Es bien sabido que al excesivo formalismo de la escuela clásica surge como respuesta el positivismo. Así señala García-Pablos: "En el primer caso, el "objeto" de la ciencia del Derecho se trasladaba al mundo ideal, al Derecho Natural. En el segundo, al mundo empírico, a la realidad metajurídica. La consecuencia, en ambos enfoques, sería muy semejante: el abandono absoluto del Derecho Positivo". García-Pablos (2005) 675. Evitar aquellos errores de radicalización pasa también por entender la Política criminal de la forma "valorativa" que se expone.

87 En este sentido sobre la dogmática penal dice Roxin: “...un sistema cerrado, concebido de esta manera, obstruye el camino para la solución de nuestro problema: aparta a la dogmática por un lado de las decisiones valorativas político-criminales, y por, otro, la incomunica de la realidad social, en lugar de dejarle abierto el camino a ella". Roxin, Claus (1972) 35. Respecto de lo mismo, pero referido a las ciencias sociales, señala Mir Puig: "Según esto, no son las normas jurídicas contempladas como conceptos lógicos, desprovistos de sentido social, el objeto de la ciencia del Derecho, sino las normas en cuanto pretenden cumplir una función social..." Mir (2002) 301.

88 Se trata de superar la dualidad que planteaba Von Liszt. Así, en palabras de Schünemann: "...en pro de la superación del concepto antitético (que se podría denominar concepto zanja Grabenkonzept) entre sistemática jurídico-penal y Política criminal y de su sustitución por un ininterrumpido sistema de relaciones y derivaciones, es decir, en pro del desarrollo de un concepto puente (Brückenkonzept)." Schünemann, Bernd (1991). "La Política Criminal y el Sistema de Derecho Penal". Anuario de Derecho Penal y Ciencias Penales, T. XLIV, Fasc. III, p. 703 .

89 Dice Bacigalupo "Política, en general, implica utilidad social. La Política Criminal presupone, por lo tanto, una concepción utilitaria del Derecho Penal y fundamentalmente de la pena: el Derecho Penal se legitima por su utilidad para la prevención del delito y, en consecuencia, para la protección de los bienes jurídicos." Bacigalupo, Enrique (1978). "Significación y Perspectiva de la Oposición Derecho Penal-Política Criminal". Revue Internationale de Droit Pénal, № 1, p. 16.

90 En este sentido Polaino Navarrete "Antes bien, el estudio de la criminalidad requiere una atención cada vez más acentuada al examen de los factores etiológicos del crimen, tanto de orden endógeno... cuanto de índole político-social, concerniente a la valoración de las dimensiones político-criminales". Polarno (1988) 10.

91 Así, Kaiser: "Es cierto que la política criminalista no puede renunciar a la utilización de datos empíricos si quiere convencer en la actualidad. Pero con ello se trasladan al proceso de valoración todas las dificultades que están relacionadas con la transmisibilidad del conocimiento experimental..." KaISER (1983) 61. 
pertenece el mundo de lo jurídico" 92 . Es en este sentido en que puede entenderse a Silva Sánchez cuando explica que la decisión político-criminal, sin importar quién sean el responsable de tomarla, no proviene directa e inmediatamente de las deducciones de las investigaciones empíricas, sino que necesariamente requieren de la intermediación de una elección de carácter claramente valorativo. "Su presentación como algo puramente empírico es una mistificación que conviene descubrir y rechazar" 93 .

De este modo, la política criminal es el punto en el que tanto los datos empíricos provenientes de las ciencias sociales ${ }^{94}$, como los aspectos normativodogmáticos se encuentran, lugar de "valoración" que impide que los meros datos procedentes de las ciencias no jurídicas puedan sin más traspasar al ámbito de lo normativo sin superar el tamiz de lo axiológico, es decir, de la "valoración", que es precisamente la esfera de competencia de la política criminal. De esta manera el material empírico no se transforma sin más en normas de "deber ser" 95 . "La elaboración de los presupuestos de ello es asunto de la política criminal científica" 96 . Así las cosas ya podemos referirnos a una política criminal que ha sumado al siempre existente criterio de eficacia, el parámetro valorativo de las garantías $^{97}$.

Es así como, entonces, se ha de comprender el aporte de Roxin en la temática que ahora tratamos. Ya es un lugar común reconocer en el profesor de Munich al principal exponente de la política criminal moderna ${ }^{98}$, básicamente caracterizada por rechazar el tajante distingo entre esta y el derecho penal ${ }^{99}$, y

García-Pablos (2005) 760. Igualmente Vidaurri Aréchiga, Manuel (1993). Estudios Juridico-penales, Guanajuato: Universidad de Guanajuato, pp. 252-257; Hormazábal Malarée, Hernán (1985). "Política penal en el Estado Democrático". En Bustos, Juan / Bergalli, Roberto, (Dirs) El Poder penal del Estado, Buenos Aires: Depalma, pp. 157-158 y Zúñiga, quien señala: "Olvidar los aspectos empíricos en aras de lo normativos, supondría un decisionismo jurídico alejado de la realidad. Diluir lo normativo en lo meramente empírico, daría lugar a un sociologismo sin direccionalidad social”. ZúNIIGA (2001) 46. Silva (2002) 95-96. En el mismo sentido Roxin; Arzt y Tiedemann (1989) 118-119; NÚNEZ (2004) 19.

94 "Esto es, en base a la realidad social que nos dice cuáles son los comportamientos insoportables para la sociedad, decidir normativa o valorativamente (con una direccionalidad social igual al desarrollo de los derechos fundamentales) como respondemos frente a ellos, con sanciones penales u otro tipo de respuestas sociales". ZÚNiGA (2001) 45-46.

Así se señala: "La Ciencia del Derecho Penal, transforma el conocimiento extrajurídico en exigencia político-criminal, y esta ha de plasmarse en norma jurídico-positiva." QUINTERo (2005) 208.

Así Göppinger señala: "Por principio, sin embargo, el material empírico no puede, como material sobre hechos, ser transformado directamente, de una forma científica, en normas de deber ser. Más bien se trata siempre, al tomar posición respecto a una semejante valoración de material empírico, de una decisión política." GöpPINGER (1975) 20.

Lo anterior es situado por Silva Sánchez a partir del aporte de Roxin, particularmente en la reforma penal alemana de los ańos 60 (proyecto alternativo). Silva Sánchez (1999) 209212, en el mismo sentido Hormazábal (2006) 81.

En este sentido, entre otros, MUŃoz Conde, Francisco (2003). Edmund Mezger y el Derecho Penal de su tiempo, Valencia: Tirant lo Blanch, p. 113.

Así, por ejemplo, señala Roxin: "El Derecho Penal sirve simultáneamente para limitar el 
antes por el contrario, incluir criterios político criminales en el análisis y elaboración de las diversas categorías del sistema penal, "...lo que ha contribuido a construir sus bases desde los fundamentos valorativos y materiales de la realidad social" 100 .

\section{(3.4) TOMA DE POSTURA: MÁS QUE UNIÓN, INTEGRACIÓN}

Es desde esta última perspectiva, como puede comprenderse el que no se requiera, el que ya no se hable de un Derecho Penal que limite una política criminal $^{101}$. Ello, pues esta ya no es concebida como mera y simple reacción punitiva, sino como una estrategia más amplia del Estado para enfrentar la dolorosa problemática social de la delincuencia, todo lo cual se enmarca en un Estado social y democrático de derecho. A su vez, tampoco se trata de una política criminal dedicada solo a ámbitos de lege ferenda, o lege lata ${ }^{102}$, y en mi opinión, tampoco de un "puente" 103 , sino de una política criminal integrada al sistema, “...la Politica Criminal ha de penetrar en las propias categorías del sistema. No creo suficiente que opere mediante meras correcciones valorativas en el posterior y ya tardío momento de la interpretación y aplicación de la ley: o de "lege ferenda". Las categorías del sistema no pueden quedar fuera del marco de la Política Criminal, sino, por el contrario, responder a sus exigencias y configurarse de acuerdo con las mismas"104.

poder de la intervención estatal y para combatir el delito. Protege, por tanto, al individuo de una represión ilimitada del Estado, pero igualmente protege a la sociedad y a sus miembros de los abusos del individuo. Estos dos componentes -el correspondiente al Estado de Derecho y protector de la libertad individual, y el correspondiente al Estado Social y preservador del interés social incluso a costa de la libertad del individuo-, si se les hace objeto de abstracción conceptual, implican rasgos antinómicos." Roxin, Claus (1976). Problemas Básicos del Derecho Penal. Traducción de Diego Manuel Luzón Peńa, Madrid: Reus, p. 59. En el mismo sentido, JeSCHECK / Weigend (2002) 3.

100 Roxin (1976) 117. Dichos asertos constituyen, hoy por hoy, una materia bastante pacífica. Entre otros Polaino (1988) 23-26. Sobre el grado garantístico de este sistema Laurenzo Copello, Patricia (2001) "El Enfoque teleológico-funcional en el sistema del delito: breves notas sobre su alcance garantístico". En Quintero Olivares, Gonzalo / Morales Prats, Fermín (Coords). El nuevo Derecho penal Español, Estudios Penales en Memoria del Profesor José Manuel Valle Muñiz, Navarra: Aranzadi, pp. 437-450.

101 Roxin (1972) 32. Sobre ello también Roxin (1976) 59.

102 En este sentido, ya Carl Stoss señalaba: "la política criminal crítica es el eslabón precedente de la legislativa". Citado por LANGLE, (1927) 26.

103 "Se adopta así una visión político-criminal que va más allá de la misión de "puente" entre el sistema penal y la realidad, "puente" que en definitiva está fuera del sistema penal-como planteara Von Liszt- dada la necesidad de superar la cosmovisión propia del liberalismo sobre la respuesta penal del Estado. Desde esta perspectiva, se afirma que la Politica criminal se ha introducido en el sistema penal, en sus mismas bases (Roxin y Hassemer), desde la llamada fase de interpretación exegética de las normas. En esta medida se habla de una "dogmática crítica", que postula la unidad sistemática entre Derecho Penal y Política criminal, en aras a que las categorías dogmáticas se configuren en atención a las exigencias político-criminales" Quintero (2005) 210 (cursiva en el original). 
Es de esta manera como, entonces, una tal política criminal ha de limitarse a sí misma, pues, no es sino la manifestación del Estado Social y Democrático de Derecho donde se forja ${ }^{105}$, de manera que no puede sino afrontar la problemática social desde los principios y valores que dan fundamento y contenido a esa forma de Estado ${ }^{106}$. De ahí que sea necesario y no solo potencial, el respeto de los derechos fundamentales, la intangibilidad de ellos, cualquiera sea la política criminal adoptada ${ }^{107}$, "La vinculación al derecho y la utilidad político-criminal no pueden contradecirse, sino que tienen que compaginarse en una síntesis, del mismo modo que el Estado de Derecho y el Estado Social no forman en verdad contrastes irreconciliables, sino una unidad dialéctica..." ${ }^{108}$.

Desde la postura que se ha venido señalando, puede comprenderse que ya no se trata de una política criminal que tenga en el Derecho penal un "límite", pues no es concebible una estrategia estatal para enfrentarse al fenómeno delictivo que esté fuera de los límites que implica en sí mismo la forma de Estado que se haya adoptado. Es así como el Derecho penal ya no se circunscribe al solo ámbito protector, que también, sino que además, para ser realistas, debe utilizarse como instrumento de la política criminal ${ }^{109}$ en pro de alcanzar, o al menos intentar, controlar los índices delictivos ${ }^{110}$. En este sentido señala Roxin: "Conforme a la situación jurídica y constitucional actual, la política criminal no tiene por objeto la lucha contra la criminalidad a cualquier precio,

105 En este sentido entre otros, De Rrvacoba y Rivacoba, Manuel (1995). "Orden Político y Política Criminal”. Revista de Derecho Penal y Criminología, No 5, pp. 841-856 y De Rrvaсова y Rrvacoba, Manuel (1980). "Relaciones del Derecho Penal con el Derecho Político". Revista Doctrina Penal, No 9, pp. 595-609; García Rivas, Nicolás (1996). El Poder Punitivo en el Estado Democrático, Cuenca: Universidad de Castilla-la Mancha, p. 45.

Señala Ferrajoli: "la subordinación de la ley a los principios constitucionales equivale a introducir una dimensión sustancial no solo en las condiciones de validez de las normas, sino también en la naturaleza de la democracia, para al que representa un límite, a la vez que la complementa" Ferrajoli, Luigi (2003). "Pasado y Futuro del Estado de Derecho". En Carbonell, Miguel (editor), Neoconstitucionalismo(s), Madrid: Trotta, p. 13 y Ferrajoli, Luigi (1994) "El Derecho como Sistema de Garantías". Revista Justicia Penal y Sociedad, ańo III, No 5, agosto, p. 15. En el mismo sentido Moccia, Sergio (1995). "Función sistemática de la política criminal. Principios normativos para un sistema penal orientado teleológicamente". En Silva Sánchez, Jesús (Editor) Fundamentos de un Sistema Europeo del Derecho Penal, Barcelona: Bosch, pp. 74-75; Muñoz (2003) pp. 113-117; Terradillos Basoco, Juan (1981). Peligrosidad social y Estado de Derecho, Madrid: Akal, p. 170; Quintero Olivares, Gonzalo (1999). "El Criminalista ante la Constitución". En AA.VV., 20 años de Ordenamiento Constitucional, Navarra: Aranzadi, pp. 375-419.

Silva (2000) 28-30.

Roxin (2000) 70.

109 En este sentido, entre otros, Durán (2006) 44-47; Vázquez Rossi, Jorge (1992). “¿De qué nos Protege el Sistema Penal?”. Revista Doctrina Penal, No 57-58, pp.82-85.

110 Binder, Alberto (1999) 64; Borja (2003a) 126; Zaffaroni, Eugenio Raúl (1995). "Abolicionismo y Garantías". Revista Jueces para la Democracia, No 24, pp. 23-25. Sin perjuicio de ello, han de recordarse aquí las acertadas palabras de Gimbernat: "el que el derecho penal sea imprescindible no significa, por supuesto, que sea imprescindible en su forma actual". Gimbernat Ordeig, Enrique (1990). “Tiene un futuro la Dogmática jurídico-penal?”. Estudios de Derecho Penal, Madrid: Tecnos, p. 150. 
sino la lucha contra el delito en el marco de un Estado de Derecho. Los componentes limitadores de la reacción pertenecen, por tanto, a la política criminal y dogmáticamente tienen que resultar tan provechosos como sus orientaciones preventivas"111.

En definitiva, podría sintetizarse diciendo que dentro de la idea de un "sistema penal" el Derecho penal será reflejo de la política criminal ${ }^{112}$ y esta, a su vez, manifestación de la forma de Estado. De ello se sigue como esencial, y no solo como potencial, que la política criminal no se base solo en criterios de "eficacia" sino que han de considerarse, de la misma manera, las garantías formales y materiales propias del Estado Social y Democrático de Derecho ${ }^{113}$, y ello se lograría, precisamente, asumiendo el rol de la política criminal desde las bases del sistema.

\section{BIBLIOGRAFÍA}

Antón Oneca, José (1986). Derecho Penal, Parte General, 2a edición anotada y puesta al día por Hernández, José y Beneytez, Luis, Madrid: Akal.

Bacigalupo, Enrique (1978). "Significación y Perspectiva de la Oposición Derecho Penal-Política Criminal". Revue Internationale de Droit Pénal, No 1.

Baigún David (1978). "Política Criminal y Derecho Penal". Revue Internationale de Droit Pénal, No 1.

Baratta, Alessandro (1999). "La política criminal y el derecho penal de la constitución: nuevas reflexiones sobre el modelo integrado de ciencias penales". Revista de la Facultad de Derecho de la Universidad de Granada, No 2.

(1998). "Política Criminal entre la Política de seguridad y la política social en países con grandes conflictos sociales y políticos". En AA.VV., Memorias Foro de Política Criminal, Bogotá: Universidad Javeriana.

(1998). "Democracia, Dogmática, y Criminología: Cuestiones Epistemológicas y Políticas de las Ciencias Penales Contemporáneas". Traducción de Ana Sabadell. En Augusto Sánchez y Venus Armenta (Coords.), Politica criminal y Sociología Jurídica, Ciudad de México: UNAM.

111 Roxin (2000) 70.

112 "Todo el Derecho penal se integra en la Política Criminal. Así, para el penalista existe una práctica identificación entre la teoría de los principios de la Política Criminal y la de los $f$ nes (y medios) del Derecho penal. Ello no debe extrañar. El Derecho penal es expresión de una Política criminal." Silva (1999) 213. (cursivas en el original). 
Baratta, Alessandro (1982). "Criminología y Dogmática penal. Pasado y futuro del modelo integral de la ciencia penal". En AA.VV., Política criminal y reforma del Derecho penal, Bogotá: Temis.

(1978). "Criminología Crítica y Política Penal Alternativa". Revue Internationale de Droit Pénal, No 1.

Barberet, Rosemary (2000). "La Investigación Criminológica y la Política Criminal". Revista de Derecho Penal y Criminología, No 2.

Barletta-Caldarera, Giacomo (1978). "Política Criminal y Derecho Penal". Revue Internationale de Droit Pénal, No 1.

Berdugo Gómez de la Torre, I.; Arroyo Zapatero, L.; Ferré Olivé, J. C.; García Rivas, N.; Serrano Piedecasas, J. R.; Terradillos Basoco, J. Ma (2004). Curso de Derecho Penal, Parte General, Barcelona: Ediciones Experiencia.

Bergalli, Roberto (1982). "Observaciones críticas a las reformas penales tradicionales". En AA.VV., Politica criminal y reforma del derecho penal, Bogota: Temis.

Beristain Ipiña, Antonio (1999). "Hoy y mañana de la Política Criminal protectora y promotora de los Valores Humanos. (La paz desde la Victimología)". En AA.VV, Política Criminal comparada, hoy y mañana, Madrid: CDJ.

Binder, Alberto (2004). Justicia Penal y Estado de Derecho, Buenos Aires: Ad Hoc.

(1999). Introducción al Derecho Procesal Penal, Buenos Aires: Ad-Hoc.

(1997). Política Criminal: De la Formulación a la Praxis, Buenos Aires: Ad-Hoc.

Blanco Lozano, Carlos (2005). "Dogmática, Política Criminal y Criminología en el Sistema del Derecho Penal". Cuadernos de Política Criminal, No 86.

Borja Jiménez, Emiliano (2003). Curso de Política Criminal, Valencia: Tirant lo Blanch.

(2003a). "Sobre el Concepto de política criminal. Una aproximación a su significado desde la obra de Claus Roxin". Anuario de Derecho Penal y Ciencias Penales, Vol. LVI.

Borja Jiménez, Emiliano (2002). Ensayos de Derecho Penal y Política Criminal, San José: Editorial Jurídica Continental.

Bueno Arús, Francisco (1978). "Algunas consideraciones de la Política Criminal de nuestro tiempo". Revue Internationale de Droit Pénal, № 1.

Bricola, Franco (1978). "Política Criminal y Derecho penal". Revue Internationale de Droit Pénal, No 1.

Bustos Ramírez, Juan (1997). "Política Criminal y Estado". En AA.VV, Estudios Jurídicos Homenaje al Profesor José Casabó Ruiz, Vol. I, Valencia: Universidad de Valencia. 
(1986). Introducción al Derecho Penal, Bogotá: Temis.

(1985). "Política Criminal y Dogmática". En Bustos, Juan / Bergalli, Roberto (Dirs) El Poder penal del Estado, Buenos Aires: Depalma.

(1983). "La Criminología". En Bergalli, Roberto / Bustos, Juan (Dirs), El Pensamiento Criminológico I, Barcelona: Península.

Bustos Juan / Hormazábal, Hernán (2004). Nuevo Sistema de Derecho Penal, Madrid: Trotta.

(1999). Lecciones de Derecho Penal, Parte General, Madrid:

Trotta.

Calderón Cerezo, Ángel / Choclán Montalvo, José (1999). Derecho Penal, Parte General. Tomo I, Barcelona: Bosch.

Cerezo Mir, José (2004). Curso de Derecho Penal Español, Parte General, Tomo I, Madrid: Tecnos.

Córdoba Roda, Juan (1978). "Evolución Política y derecho penal en España". Revue Internationale de Droit Pénal, № 1.

Cuello Contreras, Joaquín (1996). El Derecho Penal Español, Parte General, Madrid: Civitas.

Cuervo Pontón, Luis (1988). Politica Criminal, Bogotá: Universidad Javeriana.

De Rivacoba y Rivacoba, Manuel (1995). "Orden Político y Política Criminal". Revista de Derecho Penal y Criminología, No 5.

(1980). "Relaciones del Derecho Penal con el Derecho Político". Revista Doctrina Penal, No 9.

De Sola Dueñas, Ángel (1983). "Política Social y Política Criminal", en Bergalli, R. / Bustos, J. (Dirs.), El Pensamiento Criminológico II, Barcelona: Península.

Del Olmo, Rosa (1981). América Latina y su Criminología, Ciudad de México: Siglo XXI.

Délmas-Marty, Mirelle (1986). Modelos Actuales de Politica Criminal. Traducción dirigida por Barbero Santos, Marino. Madrid: SGTMJE.

Díaz-Aranda, Enrique (2006). Teoría del Delito, México: Straf.

Donini, Massimo (2003). "La Relación entre Derecho penal y política: método democrático y método científico". En Luis Arroyo Zapatero, Ulfrid Neumann y Adán Nieto Martín (Coords.), Crítica y Justificación del Derecho penal en el Cambio de Siglo, Cuenca: Ediciones Universidad Castilla-La Mancha.

Durán Migliardi, Mario (2006). Introducción a la Ciencia JurídicoPenal Contemporánea, Santiago: Ediciones Jurídicas de Santiago de Chile.

Fernández Carrasquilla, Juan (2002). Derecho Penal Liberal de hoy. Introducción a la dogmática axiológica jurídico penal, Bogotá: Ed. Jurídicas Gustavo Bañiz. 
Fernández Carrasquilla, Juan (1984). "Hacia un derecho penal de la liberación”. En AA.VV., Criminología Crítica, I seminario, Medellín: CCUM.

Ferrajoli, Luigi (2003). "Pasado y Futuro del Estado de Derecho". En Carbonell, Miguel (editor), Neoconstitucionalismo(s), Madrid: Trotta. (1999). Derechos y Garantias, La ley del más débil. Traducción ANDRÉs IBÁŇEZ, Perfecto, Madrid: Trotta.

(1994). "El Derecho como Sistema de Garantías". Revista Justicia Penal y Sociedad, año III, No 5, agosto.

García-Pablos de Molina, Antonio (2005). Introducción al Derecho Penal, Madrid: Editorial Universitaria Ramón Areces.

García Rivas, Nicolás (1996). El Poder Punitivo en el Estado Democrático, Cuenca: Universidad de Castilla-La Mancha.

Gimbernat Ordeig, Enrique (1990). "¿Tiene un futuro la Dogmática jurídico-penal?”, en AA.VV, Estudios de Derecho Penal, Madrid: Tecnos.

Gómez Benítez, José Manuel (2001). Estudios Penales, Madrid: Colex.

Gómez Martín, Víctor (2007). El derecho penal de autor, Valencia: Tirant lo Blanch.

Göppinger, Hans (1975). Criminología. Traducción de Schwarck, Luisa y LuzÁrraga, Ignacio, Madrid: Reus.

Herrero Herrero, César (2007). Politica Criminal integradora, Madrid: Dykinson.

Hormazábal Malarée, Hernán (2006). Bien Jurídico y Estado Social y Democrático de Derecho (El objeto protegido por la norma penal), 2a edición, Santiago: LexisNexis.

(1985). "Política penal en el Estado Democrático". En Bustos, Juan / Bergalli, Roberto (Dirs), El Poder penal del Estado, Buenos Aires: Depalma.

Jescheck, Hans / Weigend, Thomas (2002). Tratado de Derecho penal parte General. Traducción de Olmedo Cardenete, Miguel, Granada: Comares.

Jiménez de Asúa, Luis (1977). Tratado de Derecho Penal, Parte General, Tomo I, Buenos Aires: Losada.

KaISER, Günther (1983). Criminología. Una introducción a sus fundamentos cientificos. Traducción Belloch, José, Madrid: Espasa-Calpe.

Langle, Emilio (1927). La teoría de la Política Criminal, Madrid: Reus.

Laurenzo Copello, Patricia (2001) "El Enfoque teleológico-funcional en el sistema del delito: breves notas sobre su alcance garantístico". En Quintero Olivares, Gonzalo / Morales Prats, Fermín (Coords). El nuevo Derecho penal Español, Estudios Penales en Memoria del Profesor José Manuel Valle Muñiz, Navarra: Aranzadi.

López-Rey y Arrojo, Manuel (1985). Compendio de Criminología y Politica Criminal, Madrid: Tecnos. 
(1978). Criminologia, Madrid: Aguilar Ediciones.

Luzón Peña, Diego-Manuel (2004). Curso de Derecho Penal, Parte General, Tomo I, Madrid: Editorial Universitas.

Marer, Julio (1985). "Balance y Propuesta del Enjuiciamiento Penal del Siglo XX”. En Bustos, Juan / Bergalli, Roberto, (Dirs), El Poder penal del Estado, Buenos Aires: Depalma.

(1978). "Política Criminal y Derecho Procesal Penal". Revue Internationale de Droit Pénal, No 1.

Millitelo, Vincenzo (2003). "Dogmática penal y política criminal en perspectiva europea”. En Luis Arroyo Zapatero, Ulfrid Neumann, Adán Nieto Martín (Coords.), Critica y Justificación del Derecho penal en el Cambio de Siglo, Cuenca: Ediciones Universidad Castilla-La Mancha.

Mir Puig, Santiago (2006). Estado, Pena y Delito, Montevideo-Buenos Aires: Editorial B de F.

(2005). Derecho Penal, Parte General, Barcelona: Reppertor.

(2002). Introducción a las bases del Derecho Penal, 2a edición reimpresa, Montevideo: Editorial B de F.

(1994). El Derecho Penal en el Estado Social y Democrático de Derecho, Barcelona: Ariel.

Moreno Hernández, Moisés (2003). "Vinculaciones entre Dogmática Penal y Política Criminal”. En Ontiveros Alonso, Miguel y Peláez Ferrusca Mercedes (Coords), La Influencia de la Ciencia Penal Alemana en Iberoamérica, Tomo I, México: INACIPE.

Moccia, Sergio (1995). "Función sistemática de la política Criminal. Principios normativos para un sistema penal orientado teleológicamente". En Silva Sánchez, Jesús (Editor), Fundamentos de un Sistema Europeo del Derecho Penal, Barcelona: Bosch.

Muñoz Conde, Francisco (2003). Edmund Mezger y el Derecho Penal de su tiempo, Valencia: Tirant lo Blanch.

(1975). Introducción al Derecho Penal, Barcelona: Bosch.

Muñoz Conde, Francisco / García Aran, Mercedes (2004). Derecho Penal, Parte General, Valencia: Tirant lo Blanch.

Novoa Monrreal, Eduardo (1977). La evolución del Derecho Penal en el presente Siglo, Caracas: Editorial Jurídica Venezolana.

Núñez Barbero, Ruperto (1982) "Derecho Penal y Política Criminal". En AA.VV., Estudios Penales, Libro Homenaje al Profesor José Antón Oneca, Salamanca: Ediciones Universidad de Salamanca.

Núñez Paz, Miguel Ángel (2004). "Dogmática Penal y Política Criminal frente a la Reforma". En Rosario Diego Díaz-Santos; Eduardo Fabián Caparrós y Carmen Rodríguez (Coords.), La reforma Penal a debate, Salamanca: AUSEJP.

Ortiz de Urbina Gimeno, Iñigo (2004). "La referencia político-criminal en el derecho penal contemporáneo (Es el derecho penal la ba- 
rrera infranqueable de la política criminal, o se orienta por ella)". En Emilio Octavio de Toledo y Ubieto, Manuel Gurdiel Sierra, Emilio Cortés Bechiarelli (Coords.), Estudios penales en recuerdo del Profesor Ruiz Antón, Valencia: Tirant lo Blanch.

(2003). "Roxin y la Dogmática político-criminalmente Orientada". En Ontiveros Alonso, Miguel y Peláez Ferrusca Mercedes (Coords), La Influencia de la Ciencia Penal Alemana en Iberoamérica, Tomo I, México: INACIPE.

Pérez Luño, Antonio (2005). Derechos Humanos, Estado de Derecho y Constitución, Madrid: Tecnos.

Polaino Navarrete, Miguel (2004). Derecho Penal Parte General: Fundamentos Cientificos del Derecho Penal, Tomo I, Barcelona: Bosch.

(1988). Criminalidad Actual y Derecho Penal, Córdoba: Universidad de Córdoba.

Quintero Olivares, Gonzalo (2005). Parte General del Derecho Penal, Navarra: Aranzadi.

(2004). Adonde va el Derecho Penal. Reflexiones sobre las Leyes Penales y los Penalistas Españoles, Madrid: Thomsom-Civitas.

(1999). "El Criminalista ante la Constitución". En AA.VV., 20 años de Ordenamiento Constitucional, Navarra: Aranzadi.

Rodríguez Devesa, José María (1979). "El Derecho Comparado como Método de Política Criminal". Anuario de Derecho Penal y Ciencias Penales, T. XXXII, Fasc. I.

Rodríguez Devesa, José María / Serrano Gómez, Alfonso (1994). Derecho Penal Español, Parte General, Madrid: Dykinson.

Romeo Casabona, Carlos (1997). Dogmática Penal, Politica Criminal y Criminología en evolución (presentación). En Romeo Casabona, Carlos (editor), Dogmática Penal, Política Criminal y Criminologia en evolución, Tenerife: CECUL.

Roxin, Claus (2000). La Evolución de la Politica Criminal, el Derecho Penal y el Proceso Penal, Valencia: Tirant lo Blanch.

(1976). Problemas Básicos del Derecho Penal. Traducción de Luzón PEŇA, Madrid: Reus.

(1972). Politica Criminal y Sistema del Derecho Penal. Traducción Muñoz Conde, Francisco, Barcelona: Bosch.

Roxin Claus; Arzt, Günther y Tiedemann, Klaus (1989). Introducción al Derecho Penal y al Derecho Penal Procesal, Barcelona: Ariel Derecho.

Rusconi, Maximiliano (2005). "¿Un sistema de enjuiciamiento influido por la Política Criminal?”. En AA.VV, Estudios sobre justicia penal: homenaje al Profesor Julio B. J. Maier, Buenos Aires: Editores del Puerto.

Sainz Cantero, José (1979). Lecciones de Derecho Penal', Parte General, Tomo I, Barcelona: Bosch 
Schünemann, Bernd (1991). "La Política Criminal y el Sistema de Derecho Penal". Anuario de Derecho Penal y Ciencias Penales, T. XLIV, Fasc. III.

Schüler-Springorum, Horst (1989). Cuestiones Básica y estrategias de la Política criminal. Traducción de Elbert, Alberto, Buenos Aires: Depalma.

Serrano Gómez, Alfonso (1980). "Dogmática jurídica-política criminalcriminología como alternativa de futuro", en Anuario de Derecho Penal y Ciencias Penales, T. XXXIII, Fasc. I.

Serrano-Piedecasas, José Ramón (2001) "El Conocimiento Científico del Derecho Penal". En Nieto Martín, Adán (editor), Homenaje al doctor Marino Barbero Santos, Cuenca: Ediciones de la Universidad de Castilla-La Mancha y Ediciones Universidad de Salamanca.

Silva Sánchez, Jesús (2002). Aproximación al Derecho Penal Contemporáneo, reimpresión, Barcelona: Bosch.

(2000). Politica Criminal y Persona, Buenos Aires: Ad-Hoc.

(1999) "Reflexiones sobre las Bases de la Política Criminal". En Cerezo, J.; Suárez, R.; Beristain, A.; Romeo, C. (Editores), El Nuevo Código Penal: Presupuestos y Fundamentos, Granada: Comares.

(1997). "Política Criminal en la Dogmática: Algunas Cuestiones sobre su Contenido y Límite". En AA.VV., Politica criminal y Nuevo Derecho Penal, Libro Homenaje a Claus Roxin, Barcelona:

Terradillos Basoco, Juan (1981). Peligrosidad social y Estado de Derecho, Madrid: Akal.

Vassalli, Giuliano (1978), "Política Criminal y Derecho Penal". Revue Internationale de Droit Pénal, No 1.

VÁzquez Rossi, Jorge (1992). “¿De qué nos Protege el Sistema Penal?”. Revista Doctrina Penal, No 57-58.

Vidaurri Aréchiga, Manuel (2003). "Criminología, Política Criminal y Sistema de Justicia Penal”. En Ontiveros Alonso, Miguel y Peláez Ferrusca Mercedes (Coords), La Influencia de la Ciencia Penal Alemana en Iberoamérica, Tomo I, México: INACIPE.

Guanajuato.

Von Liszt, Franz (1995). La Idea del Fin en el Derecho Penal, Programa de la Universidad de Marburgo 1882, traducción Pérez, Carlos, Granada: Comares.

(1914). Tratado de Derecho Penal, traducción de la $18^{a}$ edición alemana y adicionado con Historia del derecho penal en España por Quintiliano Saldaña, Tomo I, Madrid: Reus.

Zaffaroni, Eugenio Raúl (1998). "La Ingeniería institucional criminal (Sobre la necesaria interdisciplinariedad constructiva entre Derecho Penal y Politología)". En Ana Messuti (Coord.), Perspectivas Criminológicas: en el umbral del tercer milenio, Montevideo: Fundación. 
(1995). "Abolicionismo y Garantías", Revista Jueces para la Democracia, No 24. Temis.

(1993). Criminología. Aproximación desde un Margen, Bogotá:

(1989). "La influencia del pensamiento de Cesare Beccaria sobre la política criminal en el mundo". Anuario de Derecho Penal y Ciencias Penales, T. XLII, Fasc. I.

Zaffaroni Eugenio; Aliaga Alejandro; Slokar Alejandro (2002). Tratado de Derecho Penal, Parte General, Buenos Aires: Ediar.

Zipf, Heinz (1979). Introducción a la Política Criminal, traducción de Miguel Izquierdo Macías Picabea, Madrid: Edersa.

ZúNíga Rodríguez, Laura (2001). Política Criminal, Madrid: Colex. 